\title{
Article \\ Aerodynamic Shape Optimisation of a Camber Morphing Airfoil and Noise Estimation
}

\author{
Robert Valldosera Martinez ${ }^{1}$, Frederico Afonso ${ }^{2}$ (D) and Fernando Lau ${ }^{2, *(D)}$ \\ 1 Instituto Superior Técnico, Universidade de Lisboa, Av. Rovisco Pais, 1049-001 Lisboa, Portugal; \\ robvalldosera@gmail.com \\ 2 IDMEC, Instituto Superior Técnico, Universidade de Lisboa, Av. Rovisco Pais, 1049-001 Lisboa, Portugal; \\ frederico.afonso@tecnico.ulisboa.pt \\ * Correspondence: lau@tecnico.ulisboa.pt
}

Citation: Valldosera Martinez, R.;

Afonso, F.; Lau, F. Aerodynamic

Shape Optimisation of a Camber

Morphing Airfoil and Noise

Estimation. Aerospace 2022, 9, 43.

https://doi.org/10.3390/

aerospace 9010043

Academic Editor: Lance Traub

Received: 30 November 2021

Accepted: 13 January 2022

Published: 15 January 2022

Publisher's Note: MDPI stays neutral with regard to jurisdictional claims in published maps and institutional affiliations.

Copyright: (c) 2022 by the authors Licensee MDPI, Basel, Switzerland. This article is an open access article distributed under the terms and conditions of the Creative Commons Attribution (CC BY) license (https:// creativecommons.org/licenses/by/ $4.0 /)$.

\begin{abstract}
In order to decrease the emitted airframe noise by a two-dimensional high-lift configuration during take-off and landing performance, a morphing airfoil has been designed through a shape design optimisation procedure starting from a baseline airfoil (NLR 7301), with the aim of emulating a high-lift configuration in terms of aerodynamic performance. A methodology has been implemented to accomplish such aerodynamic improvements by means of the compressible steady RANS equations at a certain angle of attack, with the objective of maximising its lift coefficient up to equivalent values regarding the high-lift configuration, whilst respecting the imposed structural constraints to guarantee a realistic optimised design. For such purposes, a gradient-based optimisation through the discrete adjoint method has been undertaken. Once the optimised airfoil is achieved, unsteady simulations have been carried out to obtain surface pressure distributions along a certain time-span to later serve as the input data for the aeroacoustic prediction framework, based on the Farassat 1A formulation, where the subsequent results for both configurations are post-processed to allow for a comparative analysis. Conclusively, the morphing airfoil has proven to be advantageous in terms of aeroacoustics, in which the noise has been reduced with respect to the conventional high-lift configuration for a comparable lift coefficient, despite being hampered by a significant drag coefficient increase due to stall on the morphing airfoil's trailing edge.
\end{abstract}

Keywords: camber morphing; aeroacoustics; computational fluid dynamics; aerodynamic shape optimisation

\section{Introduction}

The first subsonic jet airliners highly contributed to the generation of propulsive noise due to the high exhaust velocity of their engines. The posterior implementation of highbypass-ratio turbofans implied an overall noise reduction ranging from 20 up to $30 \mathrm{~dB}$ [1], which led to identifying airframe noise to match and even exceed the engine's contribution, especially during landing approach performance. It is within these operations that hyperlifting surfaces such as slats and flaps have an essential role, as they enable a substantial increase in lift to operate at these low-speed-related manoeuvres. However, together with the landing gear, they have proven to be the main source of airframe noise due to the complex fluid dynamic mechanisms developed around them.

Numerous experimental research works have distinguished different high-emission locations and sources along a multi-element high-lift configuration. The geometrical discontinuity of the flap-side edge results in a two-vortex system that radiates powerfully and is subjected to an unsteady three-dimensional flow behaviour [2-4]. On the other hand, several other works have localised noise sources distributed along the gaps separating slats and flaps from the wing [5]. The geometrical complexity of the slat and wing cusps causes flow separation [6,7], thereby causing an unsteady injection of vorticity to the mean flow that is trapped within the cove regions in the form of separation bubbles. These flow fluctuations cause far-field acoustic radiation. Parallel to this phenomenon, Perennes and 
Roger [7] characterised another feasible source on their multi-element two-dimensional wing at the exit of the gap between wing and flap. A strong jet was formed as a product of the wing's suction side flow mixing with the flow coming from the gap. As a consequence, the flap's trailing edge was subjected to large pressure fluctuations and thus radiating noise.

Aiming to drastically reduce noise pollution in the vicinity of airports, acoustic regulations are continuously increasing. Europe's Vision for Aviation 'Flightpath 2050' [8] has targeted the ambitious objective set by the Advisory Council for Aviation Research and Innovation in Europe (ACARE): reducing the perceived noise of a flying aircraft by $65 \%$ (i.e., $15 \mathrm{~dB}$ ) compared to levels in the year 2000. In line with airframe noise reduction regarding the flap-side edge contribution, extensive experimental research has demonstrated the effectiveness of implementing flap-tip fences, proving to decrease the peak sound level by 4 to $5 \mathrm{~dB}$ on the Ames/McDonnell-Douglas 4.7\% scale DC-10 model, conducted in the NASA Ames 40- by 80-Foot Wind Tunnel [2], as well as the 1/10 scale model wing section from the DLR Aeroacoustics Wind Tunnel Brauschweig (AWB) [6]. The Adaptive Compliant Trailing Edge (ACTE) project [9], initiated by the National Aeronautics and Space Administration (NASA) in conjunction with the U.S. Air Force Research Laboratory, incorporated the innovative Flexsys technology [10] for varying surface contours on a Gulfstream III (GIII) aircraft trailing-edge flap, attempting to increase its aerodynamic efficiency whilst reducing the emitted noise. In fact, NASA reported a $10 \mathrm{~dB}$ reduction in the airframe noise due to this system [11]. The leading edge of the main flap section connects to the main wing seamlessly. In addition, its inboard and outboard edges are connected to the wing by means of flexible sections, hence eliminating the existing gaps between wing and flap. Moreover, its trailing edge has the capability of deflecting through bending (i.e., camber morphing), a completely opposite feature to conventional deflection systems. These implementations have directed the research towards the so-called morphing structures as a substitute for conventional high-lift devices.

In 1980, NASA published an extensive study addressing the potential attractiveness of camber morphing wings at both leading and trailing edges for lift-to-drag optimisation at any flight stage [12], consequently reducing fuel consumption and operating costs. The study comprised different mechanisms that smoothly contoured the wing's leading and trailing edges independently, allowing small and large deflections for in-flight shape adaptation. Nevertheless, this change in paradigm has introduced a major challenge upon structure and material engineering. Seeking certain aerodynamic benefits with morphing structures may include smooth but also severe geometry changes, making this a difficult task to be achieved from a structural point of view. In particular, the wing skin must provide enough flexibility to allow small and large deformations whilst resisting the aerodynamic loads, a compromise that has been intensively investigated by means of different materials [13-15]. In the same direction, Tani et al. [16] investigated the flap-side edge noise reduction for a NACA23012 half-span wing by a flexible morphing slotted flap in a wind tunnel test-bed. By creating a smooth connection between the flap edge and the wing, overall noise levels during high-lift conditions were reduced whilst not compromising the wing's aerodynamic performance. On the other hand, within the EUfunded SARISTU (Smart Intelligent Aircraft Structures) project [17], the design of both adaptive leading and trailing edges led to performance improvements at subsonic speeds at the Russian Aeronautical Research Centre's Wind Tunnel. Nguyen et al. [18] have widely investigated the aerodynamic benefits of the Variable Continuous Camber Trailing-Edge Flaps (VCCTEF) morphing device, providing the wing with shape in-flight re-adaptation for aerodynamic high-lift efficiency at take-off and landing, and a reduction in cruise drag. In the previously mentioned ACTE project, drag reductions of up to $5.5 \%$ were noticed in the flight tests [11] - in other words, approaching fuel-efficient aircraft. During take-off and landing performance particularly, all the existing gaps and abrupt discontinuities between wing and conventional flap systems would be removed from the equation, a potential environment for airframe noise reduction. However, stall is expected to occur at lower angles of attack [19]. This is likely to lead to higher landing distances, which might not be a problem for a narrow-body aircraft, but would certainly be for wide-body jetliners. 
Experimental data acquisition has unequivocally identified the location and strength of noise sources around a conventional high-lift configuration, and has allowed the development of robust noise prediction semi-empirical models. However, these do not sufficiently describe the complexity of their inherent unsteady flow physics. Nowadays, as computational power is growing significantly, Computational Fluid Dynamics (CFD) is gaining prominence amongst the design and analysis of aircraft. This high-fidelity tool has provided detailed insights into the flow field that have eased the understanding of aerodynamic noise mechanisms, hence serving as a powerful complement to airfoil performance exploration and optimisation, preventing time- and cost-intensive premature model testing. Rumsey and Ying [20] have gathered a vast number of research works regarding the flow computation of high-lift multi-element configurations. Reynolds-Averaged NavierStokes (RANS) methods have been shown to provide excellent accuracy on a variety of 2-D and 3-D experimental cases regarding surface pressures, skin friction, lift, and drag, thus becoming the current most common approach. As a result, the numerical modelling of noise has also experienced noticeable progress, where CFD calculations are coupled to an acoustic prediction model by means of Lighthill's acoustic analogy [21], used in several works for flap-side edge far-field noise predictions [22]. Hence, the coupling of CFD and computational aeroacoustics (CAA), as well as their increasing predictive reliability, may become a robust complement to guide experimental testing towards a more efficient line of research and more promising implementations for (1) improvement of aerodynamic capabilities and (2) airframe noise reduction. It is within this framework that this article is presented.

The purpose of this work is to investigate the correlation between aerodynamic benefits and airframe noise reduction from morphing structures, at high-lift performance and by means of CFD and CAA. The test-case under study is the National Aerospace Laboratory (NLR) 7301 airfoil and flap as tested by van den Berg [23] at a two-dimensional level. The flow is modelled by the RANS equations in order to obtain surface pressures, lift, and drag. The same high-fidelity model is utilised for shape design optimisation (SDO) of the baseline airfoil (NLR 7301), so as to achieve a morphing airfoil with equivalent aerodynamic capabilities to those of the conventional configuration. Lastly, far-field noise contributions are calculated and compared through an acoustic-analogy-based model.

Despite the notorious lack of validation data, this paper is expected to serve as a first approach to the problem.

\section{Computational Tools}

The present section gives context to the numerical tools and methods that have been used for the structural parts of this multidisciplinary work, involving flow modelling, shape design optimisation, and far-field acoustic computations.

\subsection{Computational Fluid Dynamics Solver}

The present work has used the open-source Stanford University Unstructured $\left(S U^{2}\right)$ computational analysis and design software [24], developed by the Aerospace Design Laboratory (ADL) at Stanford University, in constant enhancement by the latter and developers worldwide. It is incorporated within a collection of numerical tools to discretise and solve Partial Differential Equation-based (PDE) problems as well as PDE-constrained optimisation problems. The flow is modelled by the compressible RANS equations for viscous flows, formulated as [24]:

$$
\frac{\partial U}{\partial t}+\nabla \cdot \boldsymbol{F}^{c}-\nabla \cdot \boldsymbol{F}^{v}=Q \quad \text { in } \Omega, t>0
$$

where $\boldsymbol{U}$ represents the vector of state variables, $\boldsymbol{F}^{\mathcal{c}}(\boldsymbol{U})$ and $\boldsymbol{F}^{v}(\boldsymbol{U})$ represent the convective and viscous fluxes, respectively, and $Q$ is the source term. The numerical solution of the RANS equations is achieved by means of the Finite Volume Method (FVM) on a mediandual, vertex-based grid. Spatial discretisation of convective fluxes is undertaken by the 
first-order accurate upwind flux-difference-splitting scheme by Roe [25], commonly used at subsonic regimes. Increased accuracy up to the second order is achieved by utilising Monotone Upstream-centred Schemes for Conservation Laws (MUSCL) [26], accompanied by the Venkatakrishnan flux limiter [27] so as to avoid solution oscillations typical of high-order schemes ("wiggly solutions") [28].

As explained in further sections, this work's mesh grids are fully composed of quadrilateral elements. Considering this fact, gradients of flow variables from viscous fluxes are given by the least-squares method so as to provide a higher-accuracy and monotonic solution [29].

The time-resolving strategy varies from steady to unsteady simulations. Steady simulations are ruled by the Euler implicit method, and will carry the weight of validating the present numerical approach for the NLR 7301 conventional high-lift configuration test-case, as well as developing the shape design optimisation to the baseline NLR 7301 airfoil. On the other hand, a dual time-stepping strategy is used within the unsteady simulations, in order to obtain surface pressure fluctuations along a certain time-span from both the flapped NLR 7301 airfoil and the ultimate morphing airfoil. Following these steps, they are processed by the acoustic framework to generate the far-field acoustic radiation.

The last steps to be addressed involve turbulence modelling. Flows from multi-element configurations are subjected to high Reynolds numbers, thereby causing the boundary layer to be largely dominated by turbulence. The present work has chosen the one-equation Spalart-Allmaras turbulence model [30] to provide the RANS system of equations' closure, as it has proven high robustness and efficiency. Moreover, it has shown good quality in handling the interaction between boundary layers and wakes (which is of great interest considering multi-element flow interactions), as well as producing fairly accurate solutions in reverse flows [31,32].

\subsection{Optimisation Algorithm}

The strategy followed is a gradient-based shape optimisation. The optimisation algorithm executed herein is the Sequential Least Squares Programming (SLSQP) optimiser from SciPy's Python library. This methodology sets characteristic airfoil properties (lift, drag, and lift-to-drag ratio) as the mathematical objective functions $(f)$ to be minimised through a set of design variables $\left(\vec{D}_{v}\right)$, used to parametrise the geometry through a parametrisation method for shape deformation. The optimisation line of search is subjected to a total of $n_{i}$ carefully designed equality-based $\left(h_{i}\right)$ and $n_{j}$ inequality-based $\left(g_{i}\right)$ constraints, which, in conjunction with the set of $\vec{D}_{v}$, define the desired optimisation path. The gradient evaluation (i.e., computation of sensitivities) is undertaken via the Discrete Adjoint method [33] due to its efficiency with the RANS equations. The sensitivity computation is the result of the derivation of the objective function $(f)$ with respect to the set of design variables $\left(\vec{D}_{v}\right)$ at each of the optimisation iterations.

The generic formulation of the constrained optimisation problem is posed as:

$$
\begin{array}{ll}
\text { minimise } & f\left(\vec{D}_{v}\right) \\
\text { with respect to } & \overrightarrow{D_{v}} \\
\text { subject to } & h_{i}\left(\vec{D}_{v}\right)=0, \quad i \in\left\{1, \ldots, n_{i}\right\} \\
& g_{j}\left(\overrightarrow{D_{v}}\right) \leq 0, \quad j \in\left\{1, \ldots, n_{j}\right\}
\end{array}
$$

\subsection{Geometric Parametrisation}

The preferred approach for geometry parametrisation is the Free-Form Deformation method (FFD) [34], which is very intuitive to use, as well as providing great versatility to deforming geometries of any level of complexity. This advantageous feature is due to the complete independence of its formulation from the geometry's mesh topology, used in works such as $[35,36]$.

The main concept of the FFD method is to create a parametric space (FFD box) into which the geometry under study is embedded. The FFD box is parametrised by several 
control points that are taken as design variables $\left(\overrightarrow{D_{v}}\right)$ by the optimisation algorithm. All the pertinent geometrical deformations are applied onto these $\overrightarrow{D_{v}}$, which are later transmitted to the geometry within.

Of relevance to the present work's interest, the FFD method allows local deformation to be imposed onto each of the design variables, even allowing us to freeze their mobility where no deformations are wanted or needed. This specific feature is used to impose structural-based constraints during the optimisation process, as will be shown in further sections.

\subsection{Aeroacoustic Framework}

Brooks et al. [37] undertook extensive research on airfoil self-noise mechanisms. Through aerodynamic and aeroacoustic wind tunnel tests of different airfoil sections, a wide illustrative database was produced. Of special interest are the identified mechanisms related to high Reynolds numbers, characteristic of subsonic high-lift performance, where turbulent boundary layers develop over most of the airfoil to finally convect at the trailing edge. The pressure fluctuations along its surface and the final flow convection act as important noise sources. High-lift configurations are also typically related to separation features such as vortex shedding or separation bubbles, providing the flow with high instabilities in charge of severe noise emissions.

For airframe noise prediction purposes, the present work has utilised an acousticanalogy based framework [38], originally designed for wind turbine aeroacoustic prediction and based on the Ffowcs Williams-Hawkings (FW-H) governing equation [39], a linearisation of the aeroacoustic problem on a moving surface $(f)$, which discretises the noise pressure perturbation $\left(p^{\prime}\right)$ into several sources represented by particular wave equations:

$$
\square^{2} p^{\prime}(\vec{x}, t)=\frac{\partial}{\partial t}\left[\rho_{0} v_{n} \delta(f)\right]-\frac{\partial}{\partial x_{i}}\left[P_{i j} n_{j} \delta(f)\right]+\frac{\partial^{2}}{\partial x_{i} \partial x_{j}}\left[H(f) T_{i j}\right]
$$

where $\square^{2} \equiv \nabla^{2}-\frac{1}{c^{2}} \frac{\partial^{2}}{\partial t^{2}}$ is the wave or $\mathrm{D}^{\prime}$ Alembertian operator in the three-dimensional space, introducing the speed of sound $c$. In addition, $\delta(f)$ and $H(f)$ are the Dirac delta and Heaviside functions, respectively, and the Lighthill stress tensor $T_{i j}=\rho v_{i} v_{j}+P_{i j}-c^{2}\left(\rho-\rho_{0}\right) \delta_{i j}$, which includes the Kronecker delta $\delta_{i j}$.

The present work is focused on the two first wave equations from the right-hand side of Equation (3). These sources are both surface sources, known as the thickness and loading noise terms:

$$
\begin{gathered}
\square^{2} p_{T}^{\prime}=\frac{\partial}{\partial t}\left[\rho_{0} v_{n} \delta(f)\right] \\
\square^{2} p_{L}^{\prime}=-\frac{\partial}{\partial x_{i}}\left[P_{i j} n_{j} \delta(f)\right]
\end{gathered}
$$

where $p_{T}^{\prime}$ and $p_{L}^{\prime}$ are the thickness and loading acoustic pressure perturbations, respectively. By definition, thickness noise (or monopole source term named after the radiation pattern of its solution) is caused by the displacement that the surface exerts onto the fluid by its movement in the normal direction, analogous to considering each of the surface panels as pistons pushing the fluid with speed $v_{n}=\vec{v} \cdot \vec{n}$, where $\rho_{0}$ is the undisturbed medium density-hence making this noise contribution geometric in nature. On the contrary, the loading noise comes from an aerodynamic point of view, which is the acceleration that the surface induces to the fluid, or the dipole term. This term is the contribution of the net force acting on the fluid from the viscous stresses and the pressure distribution along the surface, accounted for by $P_{i j}$. Again accounting for aerodynamics, the third term on the right-hand side of Equation (3), known as the quadrupole term, is in charge of modelling the non-linearities due to local sound speed variation such as shock waves. It becomes an important term for high-speed impulsive noise prediction, a matter that mainly belongs to helicopter rotors and their inherent rotational high speeds [40]. In line with this statement, a dimensional analysis by Curle [41] concluded that dipole sources are more 
efficient generators of sound in comparison with quadrupole sources for Mach numbers within a subsonic regime. In other words, dipole sources have a substantial predominance over quadrupole sources at subsonic flow conditions, which entirely define the flow during high-lift operations. Hence, together with monopole sources, they define the predominant variants for airframe noise generation within the subsequent study cases. It must be clarified that, despite not being the case of the present work, thickness and loading noise perturbations (Equations (4) and (5), respectively) exhibit a different radiation pattern to the aforementioned monopole and dipole radiation patterns for a surface in motion.

The acoustic framework is implemented with the retarded-time Farassat 1A formulation [42] in order to provide a solution to the thickness and loading wave equations. Quadrupole sources are not considered according to the above reasoning, as well as due to the high computational demand for their calculation. This formulation uses surface pressure fluctuations, which are propagated through the continuum medium (atmospheric air) until a certain desired location. The particularity of formulation 1A is its capability to discretise the wing into several surface panels (see Figure 1), to later sum each of their acoustic contributions at certain desired observer's location $\vec{x}$ and time $t$, the total pressure perturbation:

$$
p^{\prime}(\vec{x}, t)=p_{T}^{\prime}(\vec{x}, t)+p_{L}^{\prime}(\vec{x}, t)
$$

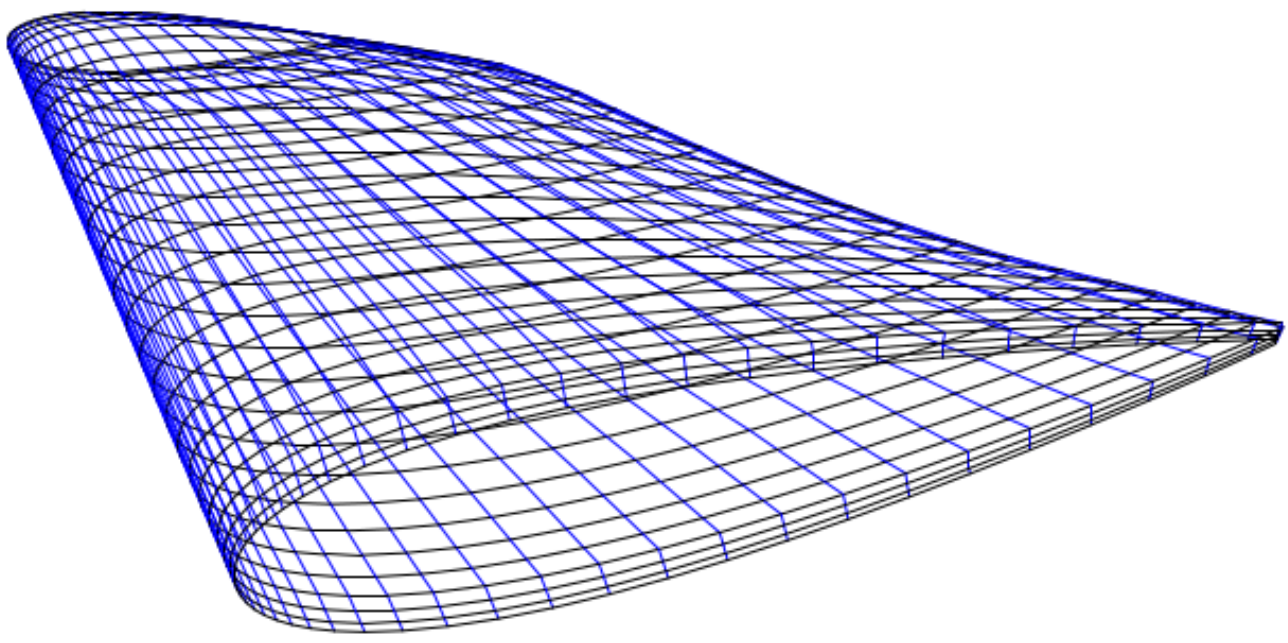

Figure 1. Example of a wing surface discretisation.

The proposed solutions are formulated as:

$$
\begin{aligned}
4 \pi p_{T}^{\prime}(\vec{x}, t) & =\int_{f=0}\left[\frac{\rho_{0} \dot{v}_{n}}{r\left(1-M_{r}\right)^{2}}\right]_{r e t} d S \\
& +\int_{f=0}\left[\frac{\rho_{0} v_{n} \hat{r}_{i} \dot{M}_{i}}{r\left(1-M_{r}\right)^{3}}\right]_{r e t} d S \\
& +\int_{f=0}\left[\frac{\rho_{0} c v_{n} M_{r}}{r^{2}\left(1-M_{r}\right)^{3}}\right]_{r e t} d S \\
& -\int_{f=0}\left[\frac{\rho_{0} c v_{n} M^{2}}{r^{2}\left(1-M_{r}\right)^{3}}\right]_{r e t} d S
\end{aligned}
$$




$$
\begin{aligned}
4 \pi p_{L}^{\prime}(\vec{x}, t) & =\int_{f=0}\left[\frac{\dot{p} \cos \theta}{c r\left(1-M_{r}\right)^{2}}\right]_{r e t} d S \\
& +\int_{f=0}\left[\frac{\hat{r}_{i} \dot{M}_{i} p \cos \theta}{c r\left(1-M_{r}\right)^{3}}\right]_{r e t} d S \\
& +\int_{f=0}\left[\frac{p \cos \theta\left(1-M_{i} n_{i}\right)}{r^{2}\left(1-M_{r}\right)^{2}}\right]_{r e t} d S \\
& +\int_{f=0}\left[\frac{\left(M_{r}-M^{2}\right) p \cos \theta}{r^{2}\left(1-M_{r}\right)^{3}}\right]_{r e t} d S
\end{aligned}
$$

and segregated by near-field terms (order $1 / r$ ) and far-field terms (order $1 / r^{2}$ ). These expressions exhibit the geometrical link between the relative position of the observer and each of the surface panels $(d s)$ or radiation direction $\left(\vec{r}_{i}\right)$, leading to the definition of the local angle between the panel's normal direction and the radiation direction $(\theta)$, at the emission time $\left(\right.$ ret; $\left.\tau_{e}\right)$. Consecutively, the acoustic pressure perturbation is propagated in the radiation direction at Mach $M_{r}=\vec{M} \cdot \hat{\vec{r}}$, reaching the observer's location at time $t$.

In order for the integral formulation of Equations (7) and (8) to be solved, numerical evaluation must be undertaken. For such a task, the implemented numerical integration algorithm is the source-time-dominant algorithm, in which the emission time of the acoustic pressure fluctuation from a certain panel is known and propagated, determining when it will reach the observer. Considering that the present work is developing high-fidelity CFD simulations in which surface pressure fluctuations are expressed in the source time reference within a previous geometrical discretisation of the wing surface, these implementations are in natural concordance.

However, the source-time-dominant algorithm leads to unequally spaced noise calculations in terms of observer time, since the generated acoustic pressure perturbation by each surface panel reaches the observer's location at a different time $t$. Therefore, in order to proceed correctly with the summation at each time-step, an interpolation algorithm is used so that pressure fluctuations are added at exactly the same observer time.

\subsubsection{Post-Processing of Aeroacoustic Data}

The subsequent total pressure signals from Farassat 1A at several observer locations are transformed from time to frequency domain by means of the Fast Fourier Transform (FFT). The resultant frequency spectra are displayed in one-third octave bands, thus facilitating the location of dominant frequencies and associated Sound Pressure Levels (SPL).

\subsubsection{Methodology Workflow Overview}

Before proceeding to the test-cases that have been used to validate the present work's computational set-up, an overview of the methodology workflow is given. The present work is subdivided into two main blocks: aerodynamics and aeroacoustics.

The starting point is the aerodynamics block, which includes all flow computations of the test-cases used for validation purposes, and the shape design optimisation of the selected baseline airfoil. All flow computations herein are steady-state solutions. The objective of this block, firstly, is to obtain an accurate solution of the multi-element configuration composed of the NLR7301 baseline airfoil plus a trailing-edge flap. The resulting aerodynamic coefficients, especially the lift coefficient, are set as the targeted aerodynamic performance to be accomplished by the morphed NLR7301 baseline airfoil. In order to do so, a shape design optimisation is performed.

Following the aerodynamics is the aeroacoustics block. Once the two aforementioned configurations prove to be aerodynamically comparable, an unsteady-state formulation is used to obtain time-dependent surface pressure data for a selected time-span and time-step, which are afterwards manipulated by the aeroacoustic framework so as to obtain each of their far-field noise contributions. 
An illustration of the methodology described in this section is depicted in Figure 2.

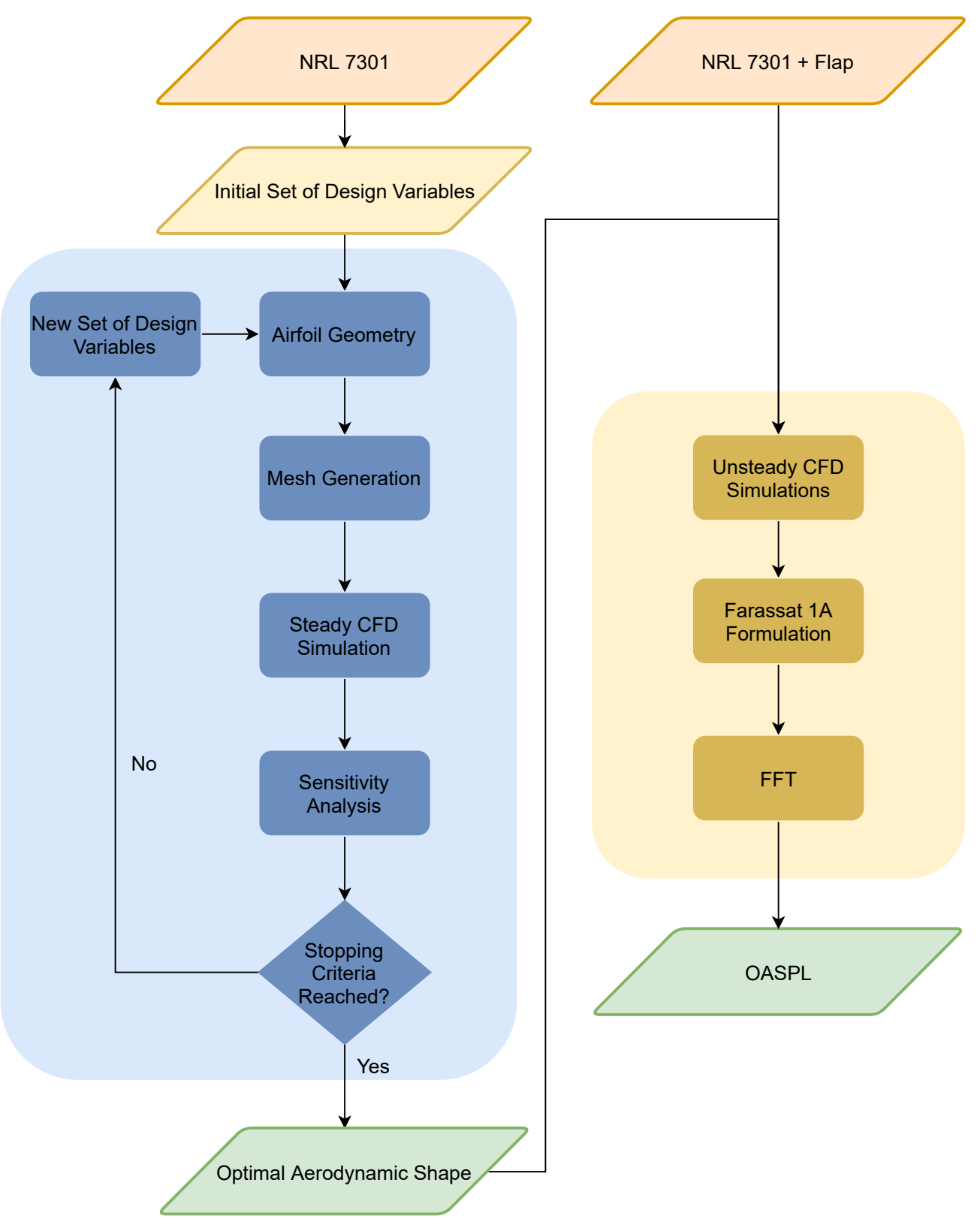

Figure 2. Methodology workflow.

\section{Computational Set-Up Validation}

The following section introduces the test-cases that have been used to validate the CFD (Section 3.1) and aeroacoustic (Section 3.2) computational set-ups.

\subsection{NLR 7301 with Trailing-Edge Flap}

The present work is focused on the conventional high-lift configuration tested by van den Berg [23], comprising the supercritical airfoil NLR 7301 and a 32\% chord trailing-edge flap, deflected $20^{\circ}$. The width of the gap between wing and flap is $2.6 \%$ chord, with mixing of the wing wake and flap boundary layer not occurring. The computational domain can be segregated into two boundaries: the airfoil surface $(s)$ and the far-field $\left(\Gamma_{\infty}\right)$. The flow solver $S U^{2}$ allows the application of physical boundary conditions that define the flow properties in contact with each of them. A no-slip condition is set onto the airfoil surface, which imposes a zero relative velocity between the surface and the gas immediately in contact with it due to viscous effects. Moreover, an adiabatic wall boundary condition 
is set, meaning that there is no heat transfer to the surface. Concerning the far field, a characteristic-based boundary condition is applied, where the state variables belonging to the free-stream $\left(\left.\boldsymbol{U}\right|_{\infty}\right)$ are applicable to the far-field boundary, meaning that the flow is undisturbed. Mathematically, these are defined as

$$
\begin{gathered}
u_{s}=v_{s}=w_{s}=0 \\
\left(\frac{\partial T}{\partial n}\right)_{s}=0 \\
\left.\boldsymbol{U}\right|_{\Gamma_{\infty}}=\left.\boldsymbol{U}\right|_{\infty}
\end{gathered}
$$

Steady flow computations have been performed with the free-stream conditions $M_{\infty}=0.185, R e=4.28 \times 10^{6}$ at ISA Sea Level conditions, at an angle of attack of $\alpha=10.1^{\circ}$. Despite the slight variation in the Reynolds number from van den Berg's experiments $\left(\operatorname{Re}=2.51 \times 10^{6}\right)$ due to considering a unit reference chord in the numerical simulations, it is not expected to have a perceivable influence on the results.

The physical domain has been meshed using a C-grid typology composed of quadrilateral elements, which account for several quality requirements, such as maximum skewness, resolution, flow alignment, and continuity between adjacent elements, as depicted in Figure 3. The domain has its boundaries at 14 chord lengths downstream and 10 chord lengths upstream in the upwards and downwards directions with a total of $233.462 \times 10^{3}$ nodes. A total of 498 nodes have been used to discretise the NLR 7301 airfoil surface, while, for the flap surface discretisation, 492 nodes have been used. A wall grid spacing of $1 \times 10^{-6} \mathrm{c}$ has been implemented to ensure the Spalart-Allmaras condition of $y^{+}<1$ to properly resolve the viscosity-affected boundary layer. A high refinement is set within the gap region between airfoil and flap. In order to guarantee a high level of flow alignment on the wake elements, the real direction of the wake has previously been tracked downstream by means of coarser meshes.

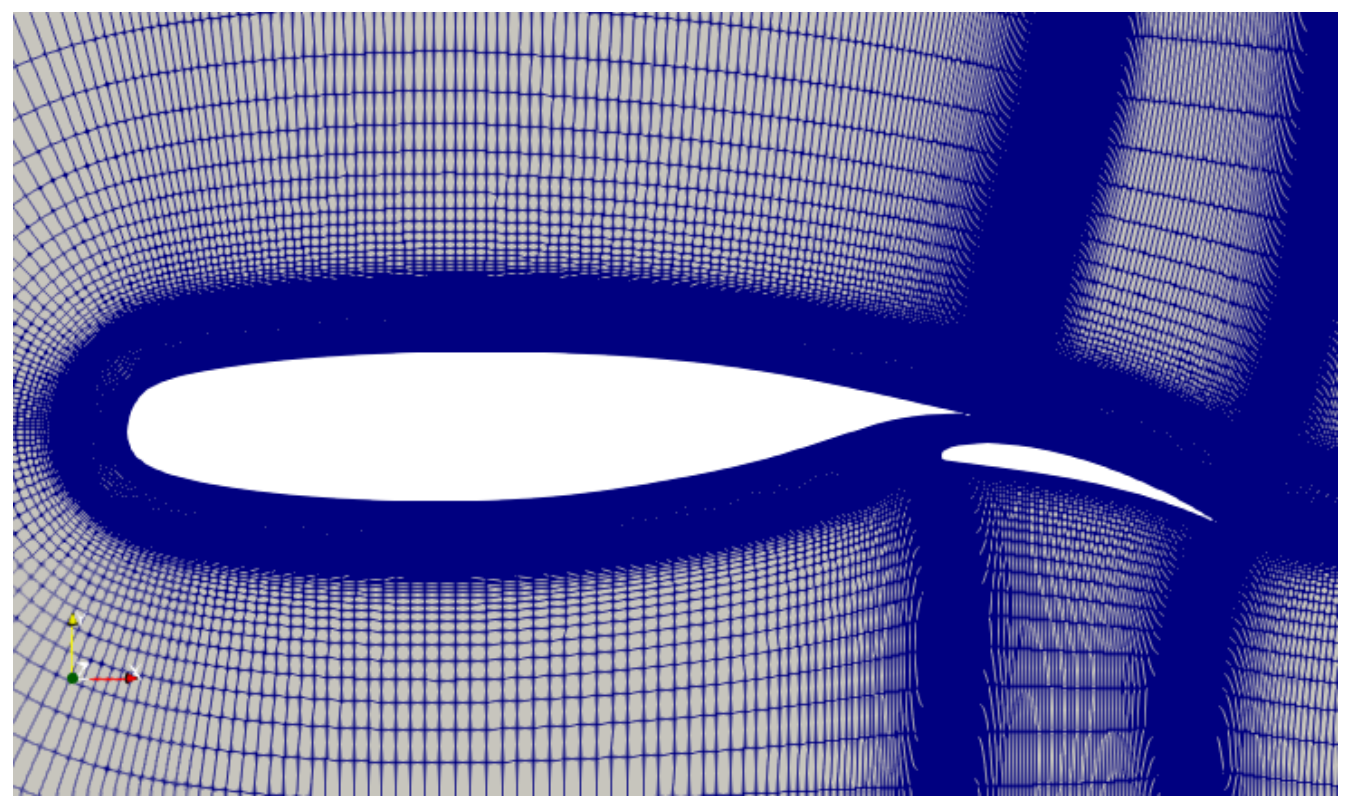

Figure 3. Mesh around NLR 7301 airfoil with trailing-edge flap.

The convergence criteria correspond to a logarithmic reduction in the density equation residual of four orders of magnitude with respect to its initial value. Its convergence history is displayed in Figure 4 alongside the development of the aerodynamic coefficients for a total of $40 \times 10^{3}$ iterations, for a Courant-Friedrichs-Levy number of $C F L=2$.

In terms of computed surface pressure distributions $\left(C_{p}\right)$ along both NLR 7301 and flap surfaces in Figure 5, results show very good agreement with experimental data. Flow separation does not occur, meaning that the flow is fully attached on both elements. Table 1 
shows a slight underprediction of the lift coefficient $\left(C_{l}\right)$ by $0.069 \%$ with respect to the experimentally obtained value, whereas the drag $\left(C_{d}\right)$ and pitching moment $\left(C_{m}\right)$ coefficients are overpredicted by $5.29 \%$ and $3.88 \%$, respectively. The well-predicted aerodynamic performance of this CFD validation test-case illustrates the potential of the $S U^{2}$ software and the Spalart-Allmaras turbulence model for subsonic multi-element flow modelling.

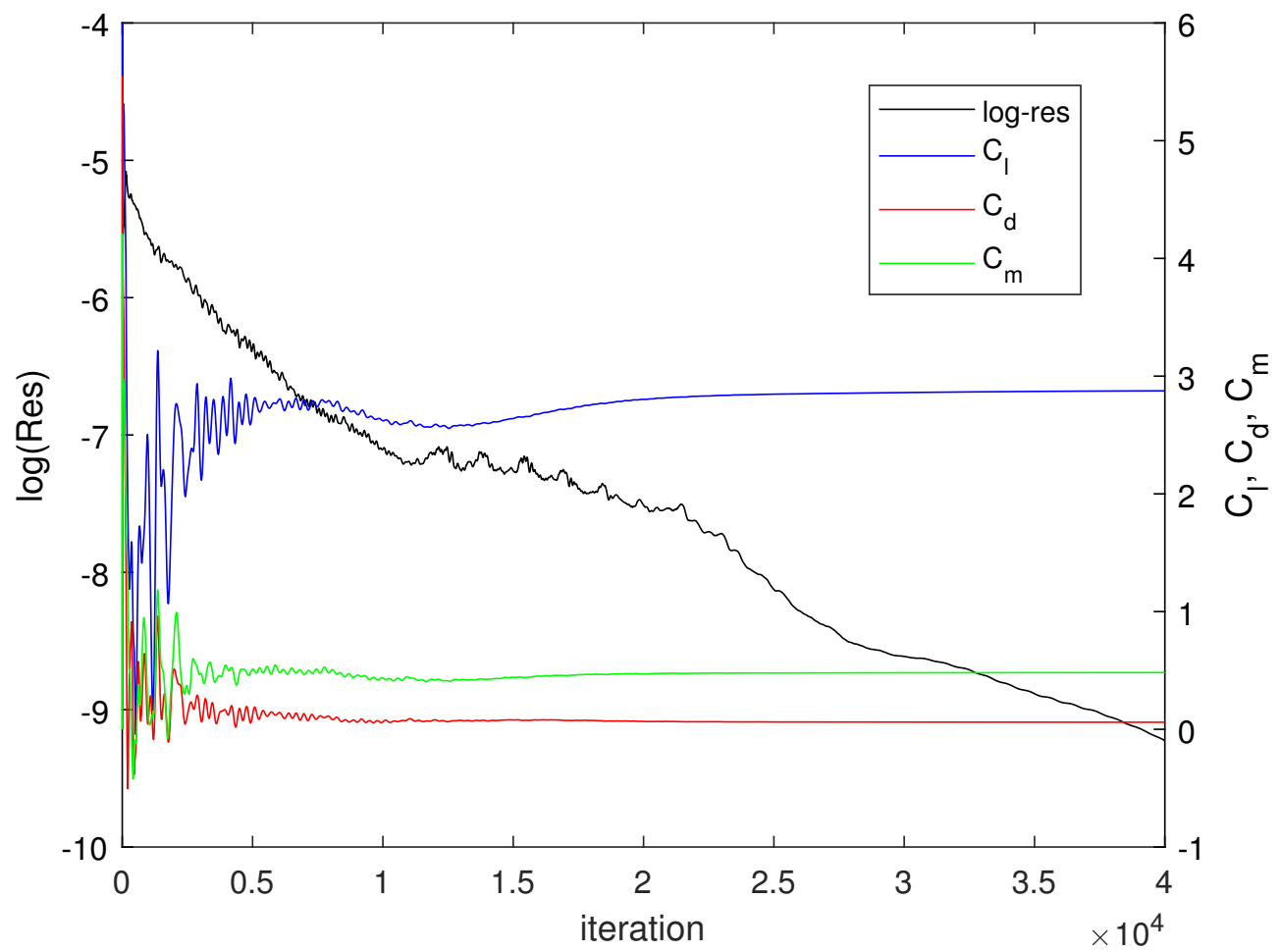

Figure 4. Residuals and aerodynamic coefficients versus iteration number of the NLR 7301 airfoil with trailing-edge flap for $M_{\infty}=0.185$ and $\alpha=10.1^{\circ}$.

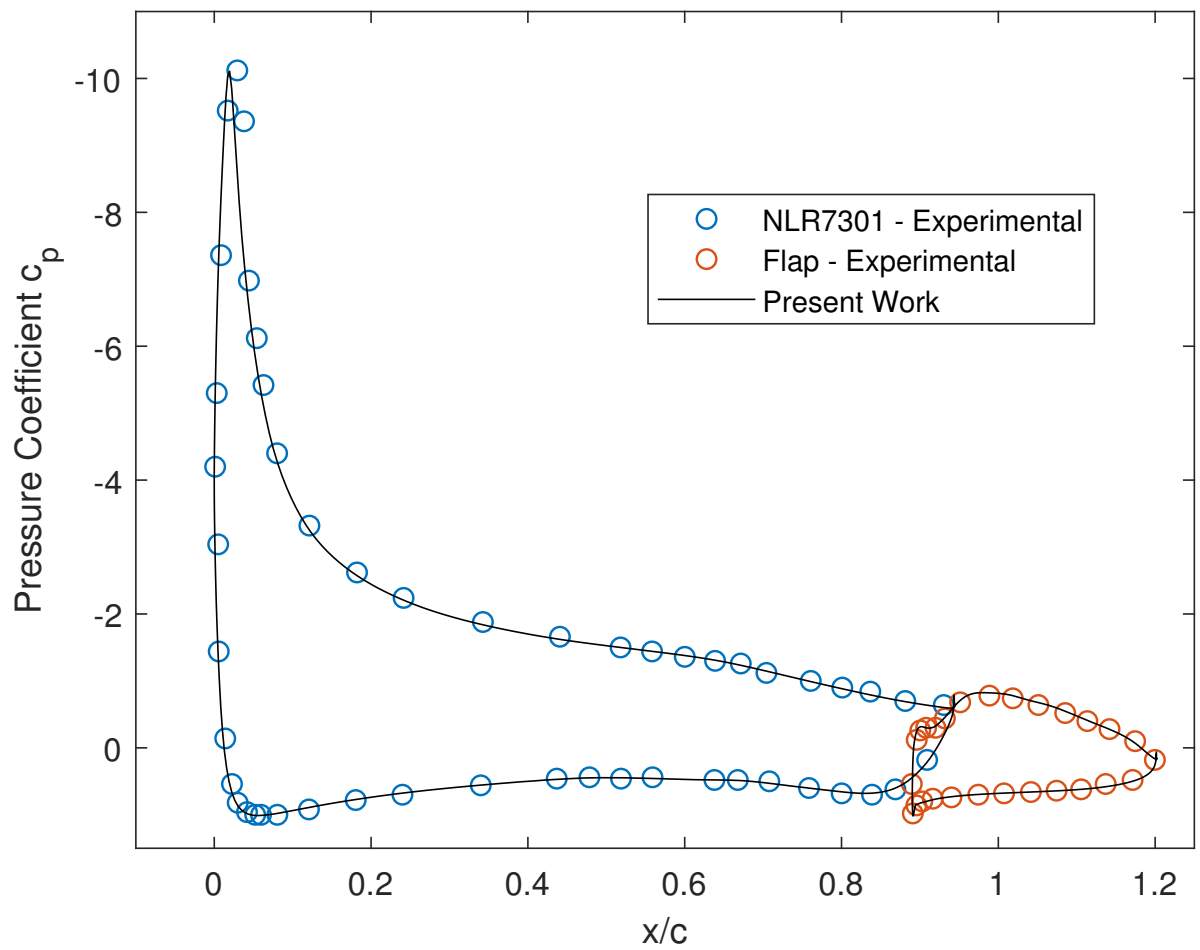

Figure 5. Comparison of experimental and numerical surface pressure distributions at $\alpha=10.1^{\circ}$ and $M_{\infty}=0.185$ of the NLR 7301 airfoil with trailing-edge flap. 
Table 1. Comparison of numerical and experimental lift and drag aerodynamic coefficients and pitching moment coefficient of the NLR 7301 airfoil with trailing-edge flap.

\begin{tabular}{cccc}
\hline & $C_{l}$ & $C_{\boldsymbol{d}}$ & $C_{m}$ \\
\hline Experimental & 2.877 & 0.0567 & 0.463 \\
Present work & 2.875 & 0.0597 & 0.481 \\
\hline
\end{tabular}

\subsection{NACA 0018 Wing}

In order to verify the numerical implementation of the Farassat $1 \mathrm{~A}$ Formulation, acoustic predictions were undertaken on a $20 \mathrm{~cm}$ chord NACA 0018 airfoil and $40 \mathrm{~cm}$ thickness, at zero angle of attack. Unsteady aerodynamic data were obtained from wind tunnel experiments developed at Delft University of Technology, at a sampling frequency of $30,069 \mathrm{~Hz}$ and a time-span of $0.2 \mathrm{~s}$ [43]. The wing was meshed with 33,280 quadrilateral panels, resulting in the acoustic pressure signal from Figure 6 at an observer located $2 \mathrm{~m}$ above the trailing edge of the central wing section.

The frequency analysis in $1 / 3$ octave bands from Figure 7 proves the overall agreement with the acoustic prediction from TU Delft's Farassat $1 \mathrm{~A}$ implementation, for the very same test-case. The frequency range from $10^{2}$ to $10^{3} \mathrm{~Hz}$ shows very good agreement between both of the implementations' sound pressure levels. Regarding the lower and higher frequency ranges, sound pressure levels are slightly overestimated with respect to TU Delft's prediction.

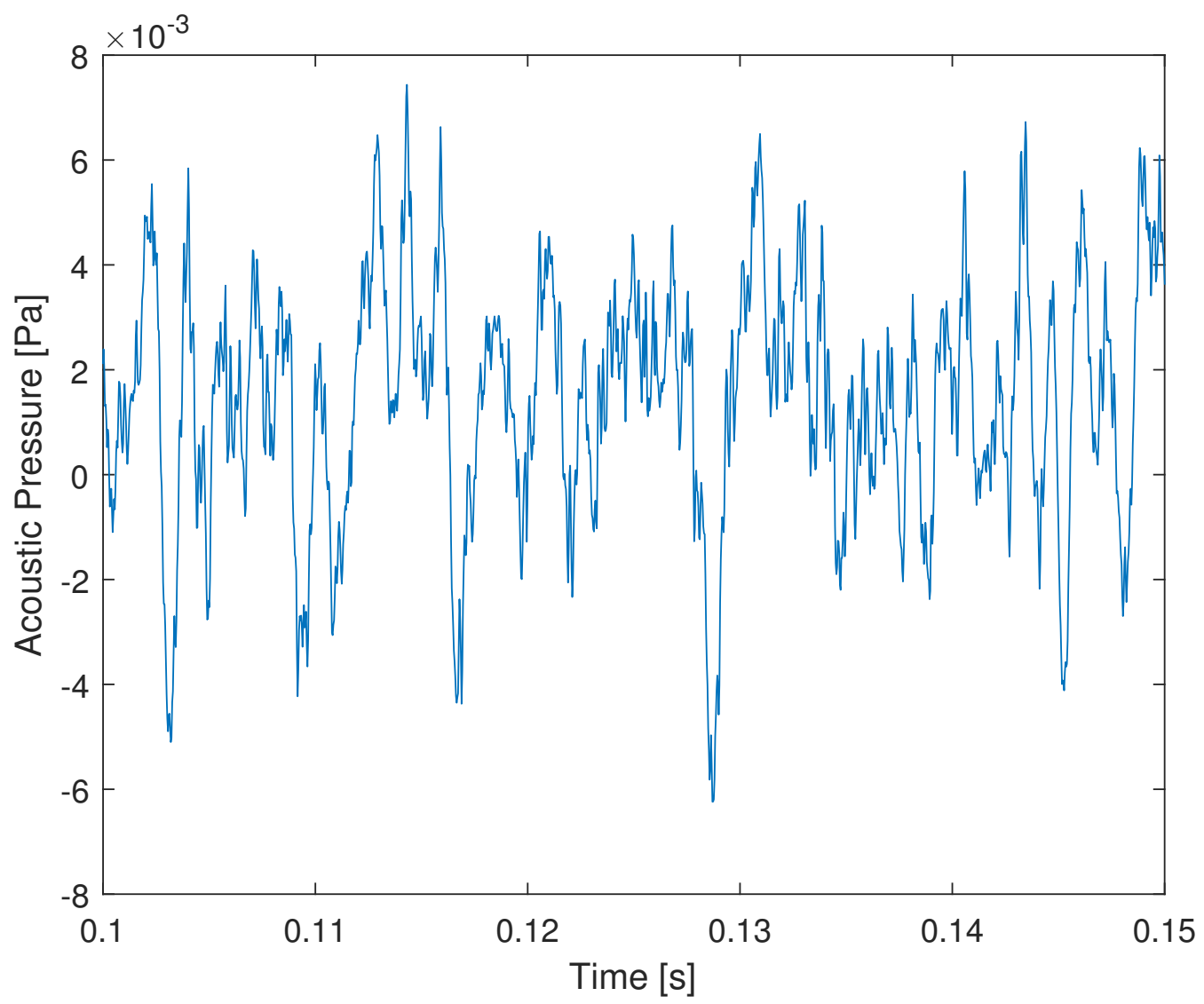

Figure 6. Close-up of computed acoustic pressure of the NACA 0018 wing. 


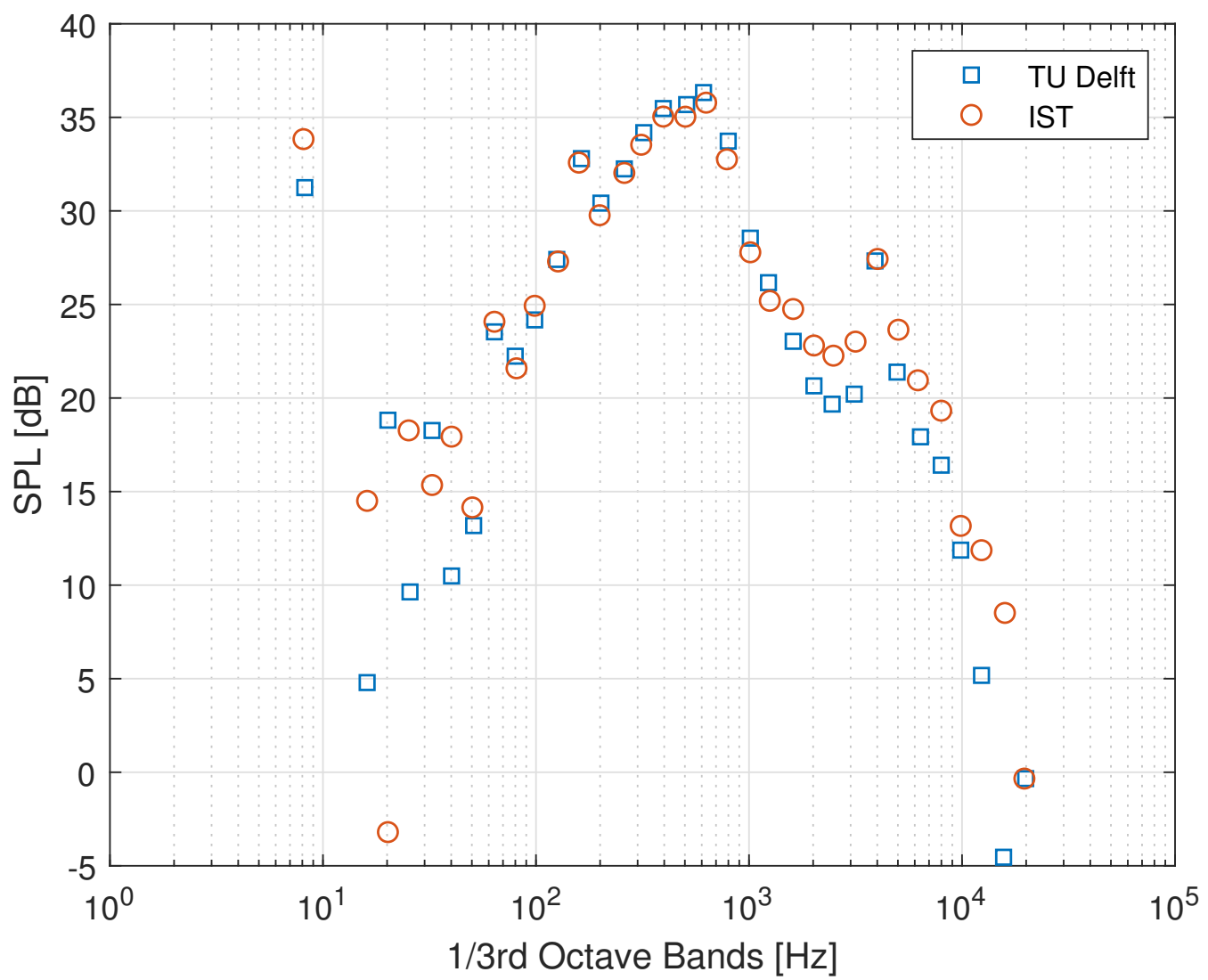

Figure 7. Comparison of $1 / 3$ octave bands between Farassat $1 \mathrm{~A}$ noise prediction codes from IST and TU Delft of the NACA 0018 wing.

\section{Results}

This section presents the results concerning the NLR 7301 aerodynamic shape design optimisation (Section 4.1), and the subsequent airframe noise prediction computation (Section 4.2).

\subsection{Aerodynamic Shape Design Optimisation}

\subsubsection{NLR 7301 Baseline Airfoil}

The shape design optimisation of the NLR 7301 baseline airfoil is undertaken in order to generate a morphing airfoil that reaches, or even surpasses, the aerodynamic performance of the flapped configuration in terms of maximum lift, whilst avoiding the drag being significantly penalised. As a result, the morphing airfoil will be capable of operating at take-off and landing performance, which requires a substantial increase in lift. The previous step in the NLR 7301 shape design optimisation is to obtain its aerodynamic capabilities at the same angle of attack and flow conditions as the conventional configuration, exhibited in Table 2, for ISA Sea Level conditions.

Table 2. Angle of attack and inflow conditions for the NLR 7301 airfoil flow computation.

\begin{tabular}{cc}
\hline Parameter & Value \\
\hline Angle of attack, $\alpha$ & $10.1^{\circ}$ \\
Mach, $M$ & 0.185 \\
Reynolds, $R e$ & $4.28 \times 10^{6}$ \\
\hline
\end{tabular}

The subsequent results are used to establish a reference in terms of initial aerodynamic coefficients before the shape optimisation. In addition, the computational set-up and the computed flow are utilised as the starting solution for the optimisation design loop. 
The flow is computed using the previously validated symbiosis between the compressible RANS equations and the Spalart-Allmaras turbulence model, in a steady simulation. The new physical domain is meshed through a design loop that is subjected to the same quality requirements as the conventional high-lift configuration from Section 3.1. Consequently, and proceeding analogously, the domain has been meshed using a C-grid typology composed of quadrilateral elements with a total of $84.650 \times 10^{3}$ nodes, depicted in Figure 8 . The NLR 7301 surface has been discretised by 351 nodes. The domain's boundaries are located 14 chord lengths downstream and 10 chord lengths upstream, in the upwards and downwards directions. A wall grid spacing of $1 \times 10^{-6} c$ ensures sufficient grid resolution to fulfil the Spalart-Allmaras condition $\left(y^{+}<1\right)$.

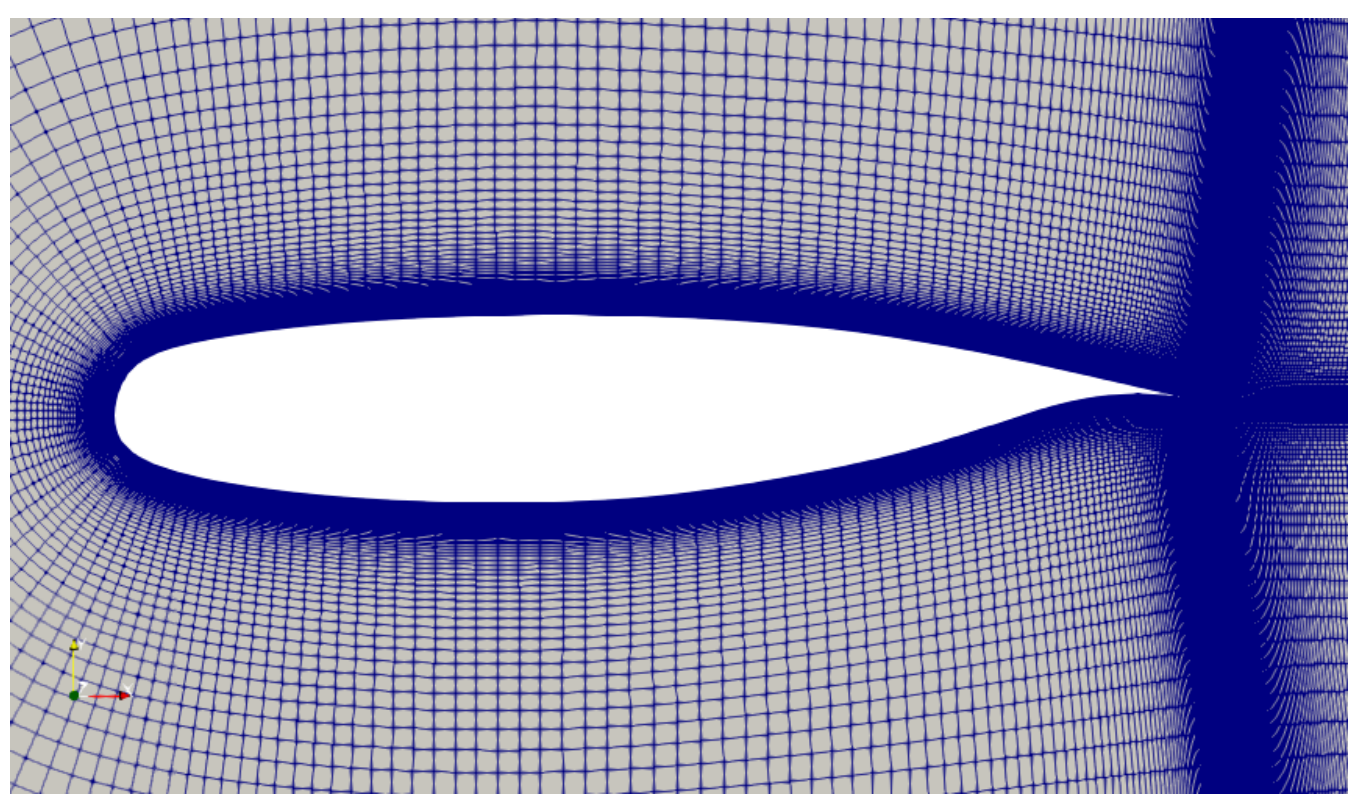

Figure 8. Mesh around the NLR 7301 baseline airfoil.

Again, the convergence criteria are set to a density residual reduction of four orders of magnitude, which has been achieved by a total of $13 \times 10^{3}$ iterations and a CourantFriedrichs-Levy number of CFL $=2$, as depicted in Figure 9. The resulting surface pressure distribution from Figure 10 clearly illustrates the difference in aerodynamics between a single element and a multi-element configuration, if compared to the surface pressure distribution from the NLR 7301 plus trailing-edge flap (Figure 5). If one focuses on each of the main elements' upper surfaces, it can easily be seen how the leading-edge pressures from the multi-element configuration are greatly increased as a result of the flap's gap influence in comparison with the single-element's, achieving their peaks close to $C_{p} \approx-10$ and $C_{p} \approx-5$, respectively. Smith [44] identified this effect as the circulation effect: the downstream element causes the trailing edge of the adjacent upstream element to be in a region of high velocity that causes a flow inclination on its rear, which effectively increases its angle of attack. Such an effect induces considerably greater circulation on the forward element, and hence greater lift.

The resulting aerodynamic capabilities in terms of lift, drag, and moment coefficients are summarised in Table 3, where the subscript $b$ refers to the baseline airfoil.

Table 3. Aerodynamic coefficients of the NLR 7301 airfoil at $\alpha=10.1^{\circ}$.

\begin{tabular}{ccc}
\hline$\left.C_{l}\right|_{b}$ & $\left.C_{d}\right|_{b}$ & $\left.C_{m}\right|_{b}$ \\
\hline 1.149 & 0.0216 & 0.032 \\
\hline
\end{tabular}




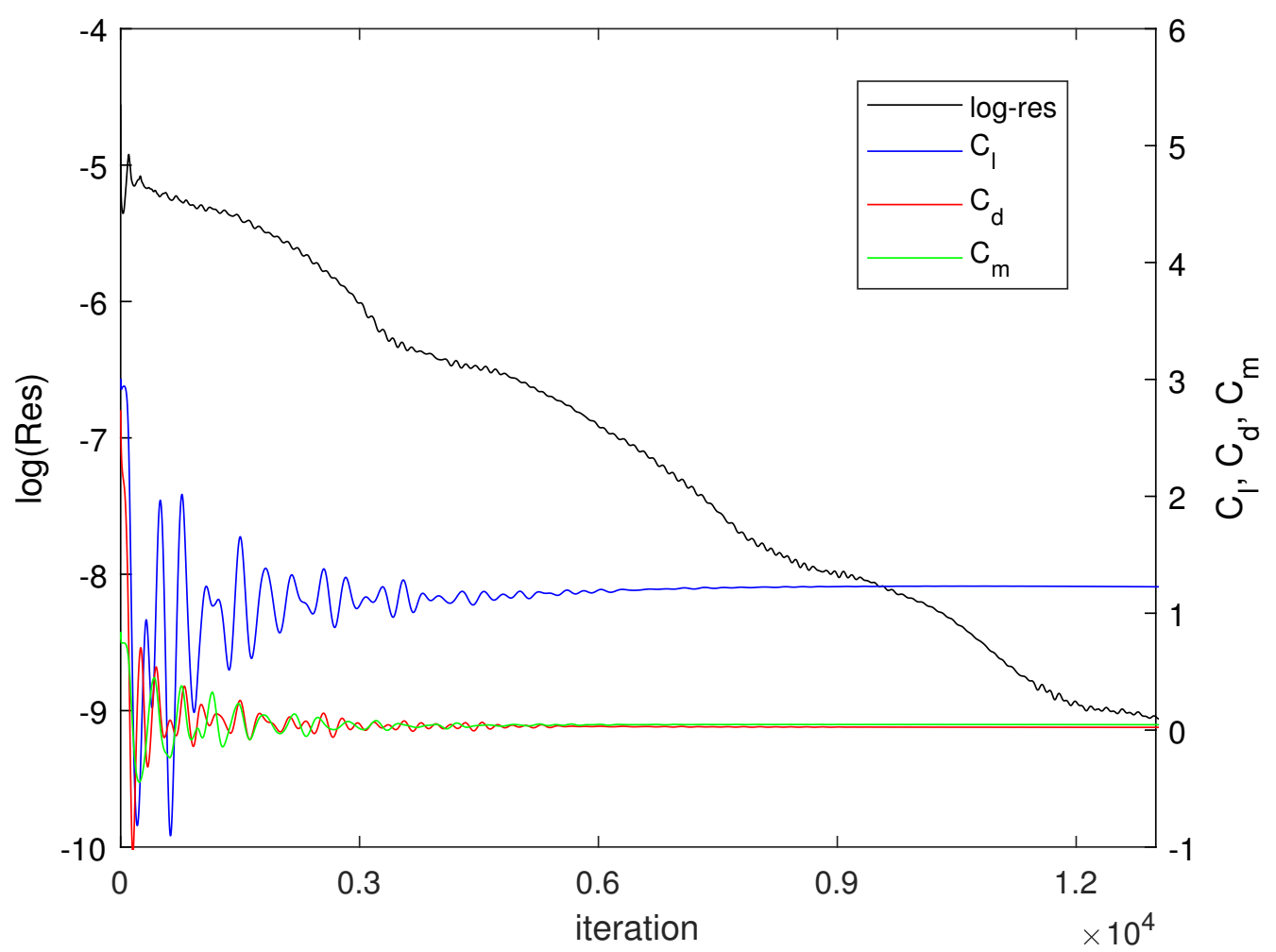

Figure 9. Residuals and aerodynamic coefficients versus iteration number of the NLR 7301 airfoil for $M_{\infty}=0.185$ and $\alpha=10.1^{\circ}$.

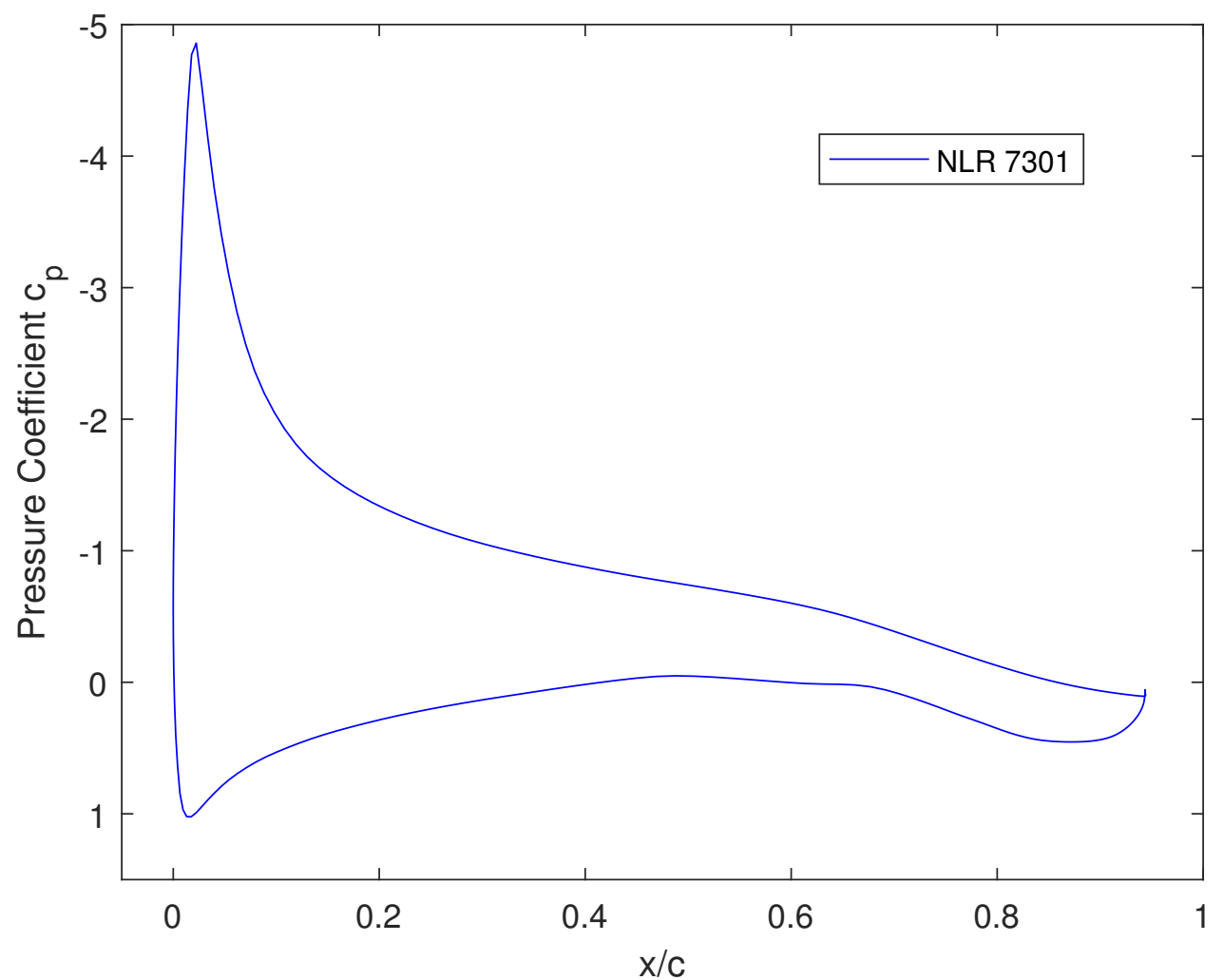

Figure 10. Numerical surface pressure distribution at $\alpha=10.1^{\circ}$ and $M_{\infty}=0.185$ of the NLR 7301 airfoil.

At this point, the main objective of the shape design optimisation of the NLR 7301 baseline airfoil arises by itself. Considering the lift coefficient of the conventional high-lift 
configuration from Section $3.1\left(C_{l}=2.875\right)$, the outcome of the optimisation design loop $\left(\left.C_{l}\right|_{\text {opt }}=C_{l}\right)$ will be achieving or surpassing a positive lift increment of

$$
\begin{aligned}
\Delta C_{l}(\%) & =\frac{\left.C_{l}\right|_{\text {opt }}-\left.C_{l}\right|_{b}}{\left.C_{l}\right|_{b}} \times 100 \\
& =\frac{2.875-1.149}{1.149} \times 100=150.2 \%
\end{aligned}
$$

with respect to its initial value, thus demanding a considerable aerodynamic lift enhancement.

\subsubsection{NLR 7301 Shape Design Optimisation}

This objective, however, is not allowed to be reached at any cost since realistic designs are sought, thereby suggesting the need to introduce several geometrical constraints to induce controlled geometry deformations. This way, the resulting optimised morphing airfoil will be as close as possible to a structurally feasible design from a short-term future point of view.

In order to address the structural limitations that ought to be imposed in the subsequent designs, one must consider the structural layout of commercial jets along their wingspan, essentially composed of a wing-box structure, ribs, and secondary structures such as the mechanisms to actuate the control surfaces and the high-lift devices, all housed by the wing skin. Nowadays, the wing box represents the main structural element and has been, over time, carefully designed, with significant design changes. Considering the sensitivity of this matter, it becomes a necessity to define a virtual wing box that must not be subjected to severe deformations during the shape optimisation procedure.

This prevents the present work from exploring the design space to the full extent where unconstrained designs might, eventually, reach the targeted lift coefficient $\left(\left.C_{l}\right|_{\text {opt }}\right)$ parallel to more competitive lift-to-drag ratios. On the contrary, these designs might also imply unreachable geometries from a structural point of view, thus not fulfilling the present work's design requirements.

As introduced in Section 2.3, FFD is the preferred parametrisation method to be used, allowing us to define an FFD box with a set of 22 design variables, as illustrated in Figure 11. It has been found that for the present work's cases, increasing the number of design variables adds complexity to achieving controllable and smooth deformations, as well as increasing the computational time cost. A wing box defined within $20 \%$ and $60 \%$ of the chord is chosen for this work to test the morphing capabilities. Chordwise wing-box positions are usually defined during the structural design process of a threedimensional wing and typical values are within $12 \%$ and $71 \%$ [45-47]. It is at this point where the potential of FFD arises, where a virtual wing box is built by freezing the design variables that are red-coloured, leaving the rest (blue-coloured) in charge of the shape design optimisation.

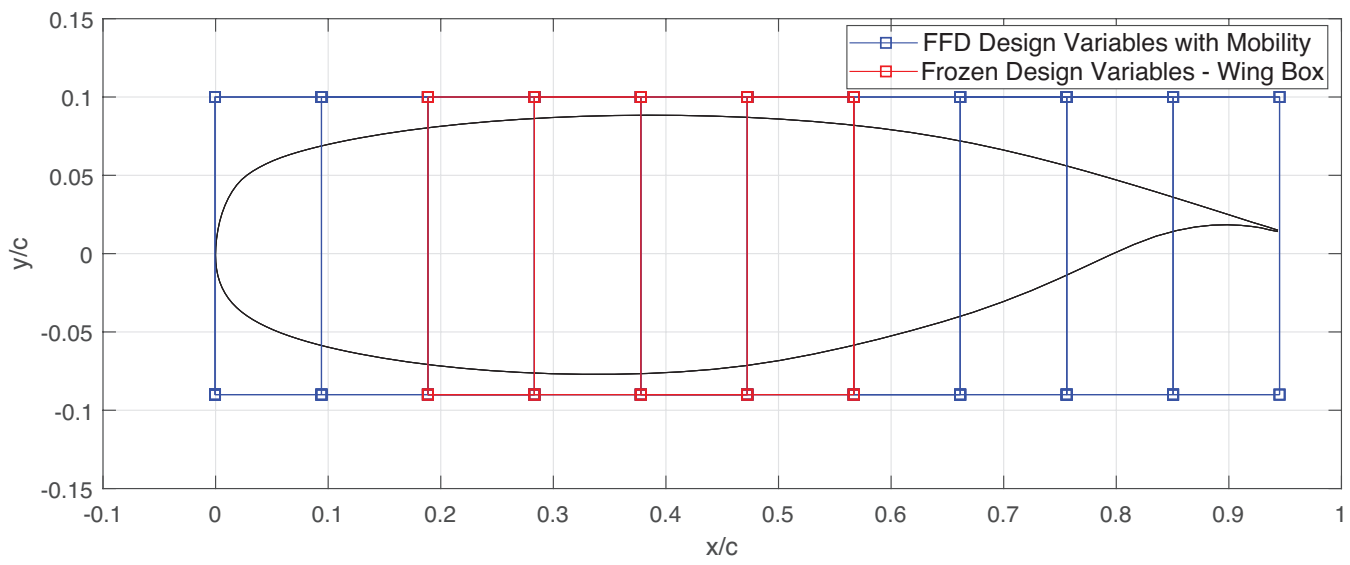

Figure 11. FFD box design variables with virtual wing box and deformable leading and trailing edges. 
Nevertheless, and in spite of the opposite nature of fixed and non-fixed design variables, the FFD formulation is built to ensure smooth surface continuity between their domains; thus, design irregularities are avoided. A last remark on how the FFD box is built addresses the margins between its boundaries and the NLR 7301 baseline airfoil, which are narrowed so that the differential between each of the control points' (or design variables) locations and the airfoil nodes is minimised, and consequently the relative coordination is increased.

Observing the non-fixed design variables from Figure 11, it is clear that the airfoil's leading and trailing edges have the responsibility of pursuing the positive increment of lift via proper geometry deformations. In conventional three-element high-lift configurations, this is achieved by deflecting leading-edge slats and trailing-edge flaps, which directly contribute to increasing the wing's chord (and sectional area) and camber.

Due to the direct proportionality between the sectional area and lift, adding slats and flaps to the main element results in a positive increment of lift. At the same time, an increase in camber will inherently result in augmenting the surface pressure difference between the suction and pressure sides of all elements, also leading to an increase in lift. The deflection of trailing-edge flaps causes the $C_{l}-\alpha$ curve to move upwards and towards the left as the deflection increases, which is translated into a higher maximum lift coefficient $\left(C_{l, \max }\right)$, as well as higher $C_{l}$ values for the same angle of attack. Regarding the deflection of leading-edge slats, their effect upon the $C_{l}-\alpha$ curve is materialised by increasing $C_{l, \max }$ and the operational angles of attack by delaying stall, for an unchanged slope of the curve. Knowing this, it may seem obvious to address these lift-increasing, stall-retardant features by proper deformations of the design variables. However, morphing an airfoil alone may imply that these aerodynamic benefits are not fully obtained, essentially due to the lack of carefully designed slat and flap lifting surfaces, as well as the lack of the slots between the elements. Consequently, it becomes imperative for the present work to understand Smith's conclusions [44] on the aerodynamic influence between the elements of a three-element configuration, in order to give some reasoning on which aerodynamic divergences to expect between the ultimate morphed airfoil and a multi-element configuration. The first one is the slat effect, in which the pressure peak of the downstream element is considerably reduced by the action of the circulation on the upstream element, consequently reducing the adverse gradients and allowing the boundary layer to much better negotiate the modified pressure distribution. In turn, the second effect (previously observed in Section 4.1.1), the circulation effect, defines the lift increase of the upstream element not by a higher angle of attack, but by a greater circulation induced by the downstream element. The trailing edge of the first is at a region of high velocity that effectively increases its angle of attack. As a result, more favourable pressure distributions are obtained, leading to an increase in lift and, if compared to the very same airfoil attempting to provide the same lift, with a lower nose pressure peak-again, alleviating the pressure gradients on the boundary layer for a more competitive performance. It is precisely this high-velocity region that provides a stall-retardant effect, called the dumping effect. Here, the boundary layer of the upstream element discharges into a flow with a higher velocity than the free-stream velocity, partially relieving it from the pressure rise imposed as it travels along the surface. As a consequence, separation problems are delayed, and higher lifts are permitted. In addition, as the boundary layer from upstream elements is dumped at velocities higher than the freestream, the final deceleration of the wake to free-stream occurs out of contact with a wall, the so-called off-the-surface pressure recovery. In other words, the pressure rise at the wake of upstream elements is diminished, hence transporting the greatest pressure recovery to freestream conditions towards the trailing edge of the whole set, and out of the domains of the elements' surfaces, helping to avoid early separation on the surface. This is a more efficient way than a deceleration in contact with a wall due to the off-the-surface deceleration being able to endure pressure rises in much shorter distances, compared to boundary layers. Lastly, it must be noted that properly designed multi-element airfoils develop their own boundary layer without any merging between adjacent elements, the fresh-boundary-layer effect, also being the present work's case. This works as a safety measure against separation, 
as breaking up the surface into several elements favours the development of thin boundary layers, which can withstand greater pressure gradients than thicker ones.

It may seem reasonable to categorise these lift-empowering, stall-retardant effects as boundary layer control effects. In a way, this is precisely what the aerodynamics of a multi-element airfoil provide thanks to the gaps, which widen the aircraft's operational range and lead its performance to be feasible at higher angles of attack without boundary layer separation.

This gives the present work a crucial hint of what is to be expected from a morphed single element. If a substantial lift increase is to be achieved by means of the non-fixed design variables (refer to Figure 11), there exists no other way than a slat and flap-like deformation, aiming to increase the curvature as well as the chord and sectional area. However, the lack of slots and the aforementioned favourable aerodynamics will, most certainly, have a negative impact concerning stall. In this case, the absence of any external aid will force the boundary layer to develop under harsher conditions, whilst still having to fulfil our challenging demands.

Conclusively, considering the high probability of a partially separated region, it will be this work's duty to minimise its impact on the ultimate morphed airfoil's lift-to-drag ratio.

\subsubsection{Optimisation Geometrical Constraints}

Near-future structural feasibility will not only be achieved by the imposition of a virtual wing box but also by geometrical constraints, which will orchestrate the behaviour of the design variables through the entire shape design optimisation of the NLR 7301 baseline airfoil. The user's direct influence upon the design path (or line of search) increases its accuracy towards the desired outcome.

One of the most delicate features to have under control during the whole process is the airfoil's minimum thickness $\left(\left.t_{\min }\right|_{\text {opt }}\right)$, which is set to be greater than $5 \%$ of the baseline airfoil's maximum thickness $\left(t_{\left.\max \right|_{b}}\right)$ :

$$
\left.t_{\min }\right|_{\text {opt }} \geq 0.05 \times\left. t_{\max }\right|_{b}
$$

due to manufacturability reasons. This is directly related to the chord increase that the baseline airfoil will be forced to undertake via a chord constraint. If only surface stretching was imposed, the probability of large areas below the minimum manufacturable thickness would become substantial, especially at the trailing edge, where thickness is already of low values. As a consequence, high aerodynamic loads over these thin areas could lead to a structural failure. In addition, an area constraint is implemented to help support this concept, with which the sectional area will also be forced to increase in order to avoid excessively large thin areas. All these constraints together are intended to emulate the geometrical implications of deflecting conventional slats and flaps.

In order for these concepts to be materialised as constraints, the following crude approach was used: in the conventional high-lift configuration, the flap represents $32 \%$ of the NLR 7301's chord, and an added sectional area of 30\%. Analogously to the morphed airfoil, the present work will limit its chord's positive increment to a maximum value of $32 \%$, while its sectional area will be forced to increase at least half of the flap's area:

$$
\begin{gathered}
\left.c\right|_{o p t} \leq\left. c\right|_{b}+0.32 \times\left. c\right|_{b} \\
\left.A\right|_{o p t} \geq\left. A\right|_{b}+0.5 \times\left(0.3 \times\left. A\right|_{b}\right)
\end{gathered}
$$

The intentions behind these constraints become now visible. The sectional area is given more freedom to explore the design space compared to the chord, as no upper limitations are set. The expected consequence is a thickness compensation during the surface stretching caused by the chord increase. Again, despite the fact that these are only rough approximations, they allow us to predefine the outer layer of the shape design optimisation's DNA - the governing global behaviour of the deformations. 


\subsubsection{NLR 7301 Morphing Design}

The present work's target lies amongst the infinite solutions within. If the line of search is to be fully and accurately parametrised, the core (or inner layer) of the deformations' behaviour must be set and this implies coding the non-fixed design variables.

Each of the design variables depends upon its own associated bi-dimensional vector of scale factors $S F_{i}=\left(x_{\text {mov }}, y_{\text {mov }}\right)$ in the horizontal and vertical directions, respectively. Their value acts directly upon the amplitude and direction of the surface deformation to be applied at each optimisation step, where a higher absolute value of a scale factor comes with greater achievable deformations.

The definitive set of scale factors was obtained as a result of the reasoning presented in Section 4.1.2, where the line of search of the shape optimisation was to be set so as to emulate a slat $\left(-x_{\text {mov }},-y_{\text {mov }}\right)$ and flap-like $\left(x_{\text {mov }},-y_{\text {mov }}\right)$ deployment for curvature increase, ultimately having defined them for each design variable, as presented in Table 4 , where $I_{\text {ind }}=[0,10]$ corresponds to their indexed position along the $x$ axis, from leading to trailing edge, while $J_{\text {ind }}=[0,1]$ along the y axis or, in other words, corresponding to the suction and pressure sides, respectively.

Table 4. Scale factors at each of the non-fixed FFD design variables for the NLR7301 SDO.

\begin{tabular}{ccc}
\hline Design Variable: $\left(\boldsymbol{I}_{\text {ind }}, \boldsymbol{J}_{\text {ind }}\right)$ & $\boldsymbol{x}_{\text {mov }}$ & $\boldsymbol{y}_{\text {mov }}$ \\
\hline$(0,0)$ & -1.0 & -1.0 \\
$(0,1)$ & -1.0 & -1.0 \\
\hline$(1,0)$ & -1.0 & -1.0 \\
$(1,1)$ & -1.0 & -1.0 \\
\hline$(7,0)$ & 0.6 & -0.75 \\
$(7,1)$ & 0.6 & -0.75 \\
\hline$(8,0)$ & 0.5 & -0.75 \\
$(8,1)$ & 0.5 & -0.75 \\
\hline$(9,0)$ & 0.4 & -0.6 \\
$(9,1)$ & 0.4 & -0.6 \\
\hline$(10,0)$ & 0.225 & -0.375 \\
$(10,1)$ & 0.225 & -0.375 \\
\hline
\end{tabular}

The partition between leading and trailing edge becomes clearly noticeable with the gap spanning from $I_{\text {ind }}=[2,6]$, which corresponds to the virtual wing box. The leading edge has been given a higher absolute value of scale factors for both directions if compared to the trailing edge, which is translated into more freedom of movement. The reason is a higher concentration of area in the leading edge that can be exploited, and hence a lower probability of minimum thickness constraint violation or large low-thickness areas due to surface stretching. In line with this reasoning, the trailing edge design variables have gradually been given a decreasing scale factor amplitude as they approach the airfoil's lowthickness trailing edge, thus implementing a more restrictive local movement if compared to the leading edge.

The definition of the geometrical constraints plus the design variables $\left(\vec{D}_{v}\right)$ sets the foundations that lead to this work's targeted designs. Thus, together with the lift coefficient $C_{l}$ being set as the objective function to be maximised, the mathematical definition of the SDO can now be displayed:

$$
\begin{array}{ll}
\text { maximise } & C_{l} \\
\text { withrespectto } & \overrightarrow{D_{v}} \\
\text { subjectto } & \left.t_{\text {min }}\right|_{\text {opt }} \geq 0.05 \times\left. t_{\text {max }}\right|_{b} \\
& \left.c\right|_{\text {opt }} \leq\left. c\right|_{b}+0.32 \times\left. c\right|_{b} \\
& \left.A\right|_{\text {opt }} \geq\left. A\right|_{b}+0.5 \times\left(0.3 \times\left. A\right|_{b}\right)
\end{array}
$$


As previously introduced, the starting solution for the shape design optimisation is the NLR7301 steady RANS case from Section 4.1.1. The same computational approach has been used for the intermediate stages during the optimisation process, a coupling between the compressible RANS and Spalart-Allmaras turbulence model in a steady-state simulation. The morphing evolution from the baseline airfoil up to the definitive morphing airfoil is depicted in Figure 12.

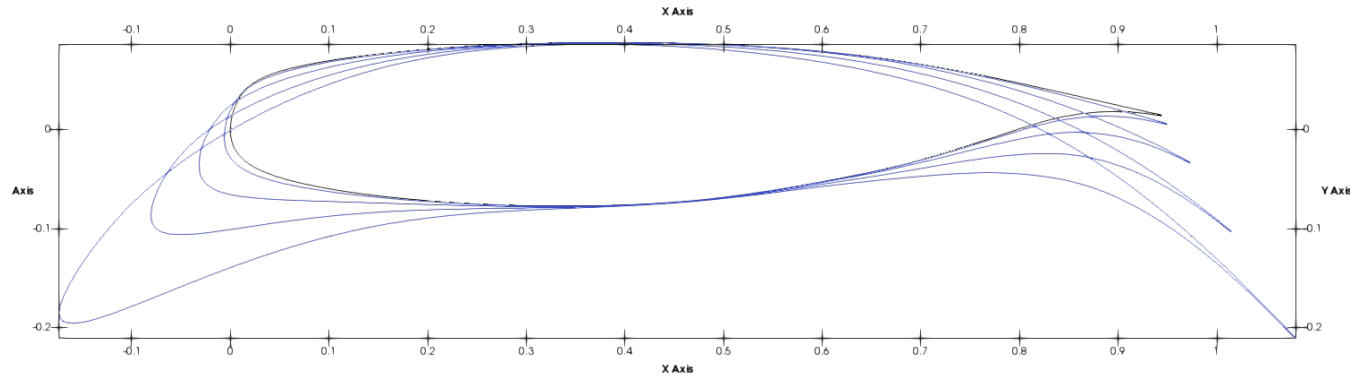

Figure 12. SDO NLR7301 morphing stages.

A comparison between the geometrical parameters from the baseline airfoil NLR7301 and the definitive morphing airfoil is shown in Table 5.

Table 5. Dimensionless chord and area from NLR7301 and definitive morphed airfoils.

\begin{tabular}{ccc}
\hline Parameter & Baseline & Optimised \\
\hline Chord & $\left.c\right|_{b}=0.9443$ & $\left.c\right|_{\text {opt }}=1.2528$ \\
Area & $\left.A\right|_{b}=0.1083$ & $\left.A\right|_{\text {opt }}=0.1342$ \\
\hline
\end{tabular}

The relative chord and area increase of the morphed airfoil are $\Delta_{c}(\%)=32.6$ and $\Delta_{A}(\%)=23.92$, meaning that the geometrical constraints as well as the targeted morphing behaviour have been respected: a comparable overall chord increase to $32 \%$ from the flap deployment, and an area increase that has surpassed the $15 \%$ set as the minimum in the geometrical constraints.

From a general point of view, smooth deflections have been achieved towards the desired directions thanks to the scale factors' amplitudes and their sign convention, fairly emulating the deflection of a slat and flap devices for curvature increase. Concerning the leading edge, applying less restrictive scale factors has not led to problematic low-thickness areas, while the trailing edge, even subjected to a more restrictive margin of movement and not having surpassed the minimum thickness constraint, will certainly be the most challenging one from a structural point of view due to a larger low-thickness area, as it will have to withstand the aerodynamic loads without a structural collapse.

Regarding the aerodynamics, Figure 13 alongside Table 6 show how the lift and drag coefficients have evolved during the shape design optimisation from start to end and at the different intermediate stages of the process. The values shown are the last values of each of the iterative processes for every design, the convergence criteria of which correspond to a logarithmic reduction in the density equation residual of four orders of magnitude.

On the other hand, considering that unsteady features were highly likely to arise and not properly captured by a steady formulation, a maximum of $20 \times 10^{3}$ iterations per design was set in case the convergence criteria were not fulfilled.

The trend in the lift curve shows the desired behaviour, boosting its climb rate from the second design up to a maximum value of $\left.\mathrm{Cl}\right|_{\text {opt }}=2.854$, which is considered valid for comparison with the conventional high-lift configuration and its numerically obtained $\mathrm{Cl}$ value $(\mathrm{Cl}=2.875)$. This substantial lift increase is accompanied by a similar trend in the drag curve, which starts increasing its rate of climb from the third to the fourth stage of the SDO, achieving a maximum value of $\left.C d\right|_{\text {opt }}=0.1209$, a dramatic increase if compared to 
the NLR7301 baseline airfoil, and an indicator of an undesired unsteady feature due to the high curvature of the last designs. Both aerodynamic coefficients are plotted in Figure 14.

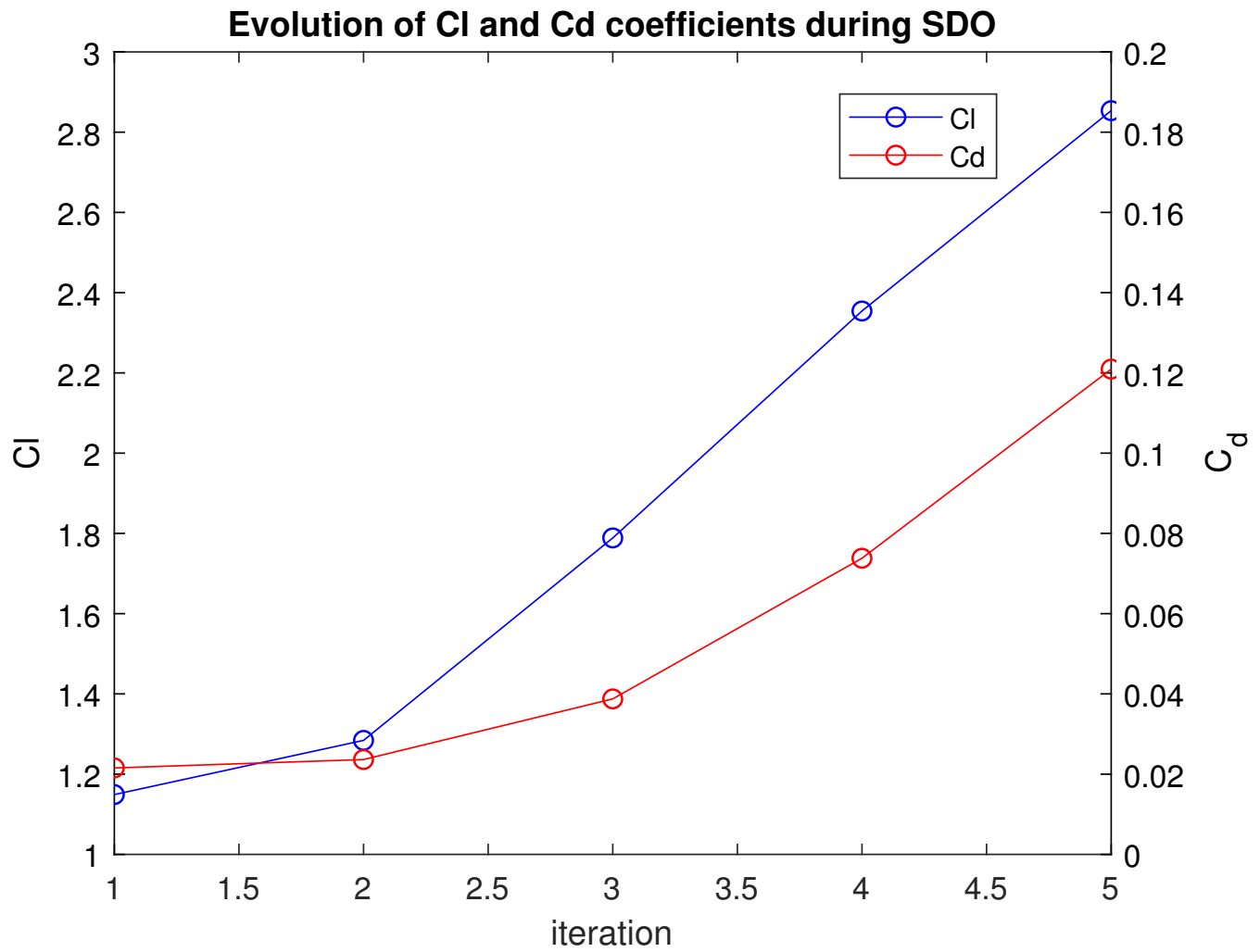

Figure 13. Evolution of $C_{l}$ and $C_{d}$ coefficients during the NLR7301 SDO for $M_{\infty}=0.185$ and $\alpha=10.1^{\circ}$

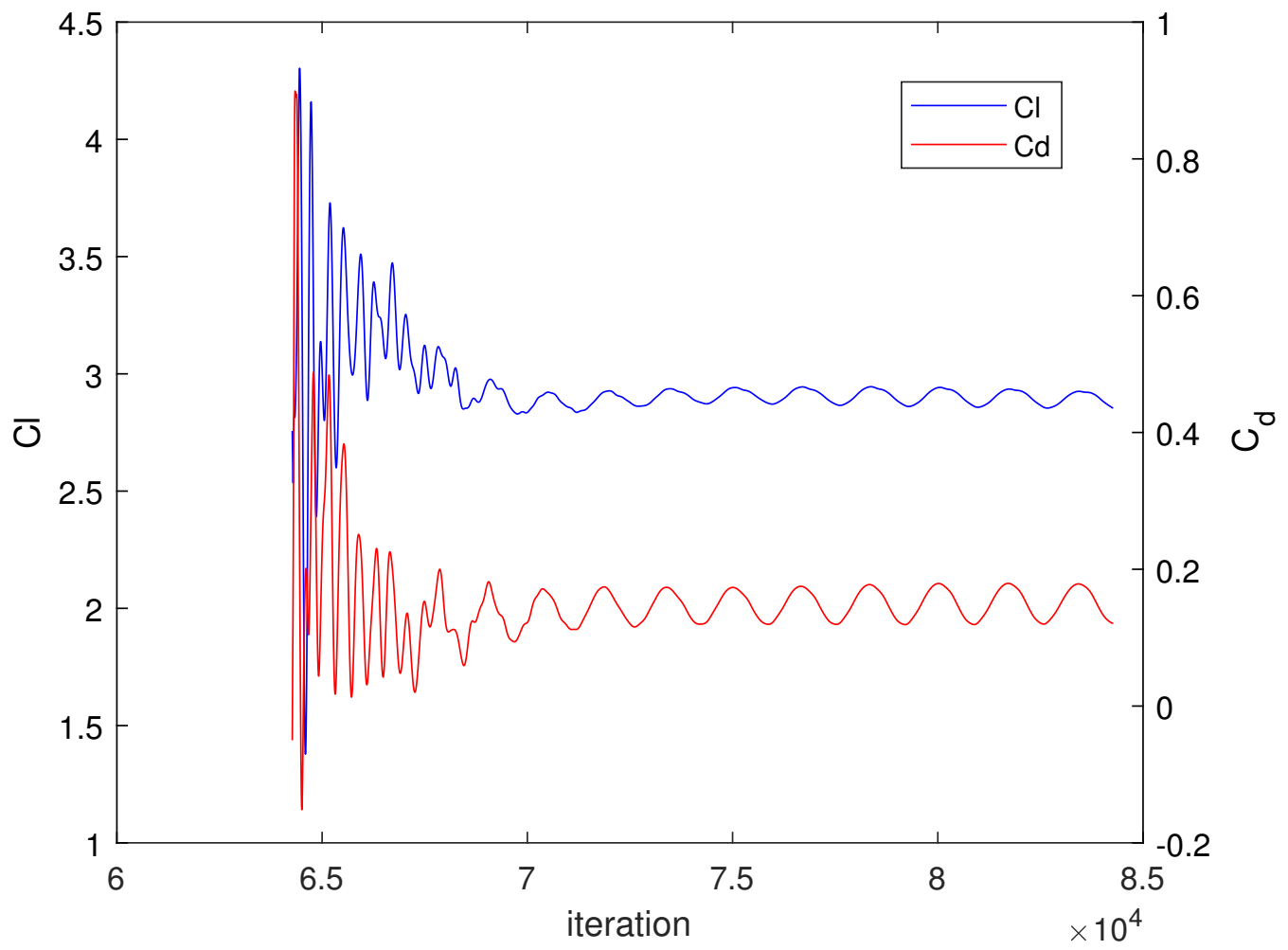

Figure 14. Steady RANS solution of the aerodynamic coefficients from the definitive morphed airfoil for $M_{\infty}=0.185$ and $\alpha=10.1^{\circ}$. 
Table 6. Aerodynamic coefficients during the SDO.

\begin{tabular}{ccc}
\hline Iteration & $C_{\boldsymbol{l}}$ & $\boldsymbol{C}_{\boldsymbol{d}}$ \\
\hline 1 & 1.149 & 0.0216 \\
2 & 1.284 & 0.0236 \\
3 & 1.789 & 0.0387 \\
4 & 2.354 & 0.0738 \\
5 & 2.854 & 0.1209 \\
\hline
\end{tabular}

Clear oscillations on both coefficients are observed, meaning that the morphed airfoil hides unsteady features that cannot be described by the steady formulation or to make the solution converge: the mean value from each of the oscillating aerodynamic coefficients is $\overline{C l}=2.85$ and $\overline{C d}=0.14$ for the lift and drag, respectively. For this reason, the natural step that followed these results was to address the unsteadiness via an unsteady simulation to properly describe it. As previously introduced, a dual-time stepping strategy was used. The sampling frequency was set at $f_{s}=1000 \mathrm{~Hz}$, equivalent to implementing a time-step of $\Delta_{t}=1 \mathrm{~ms}$. The solution reached a stable behaviour after a time-span of $t=0.7 \mathrm{~s}$ and outputted slightly different mean lift and drag coefficients, displayed in Table 7.

Table 7. Morphed airfoil mean lift and drag coefficients from the unsteady simulation.

\begin{tabular}{cl}
\hline Coefficient & Value \\
\hline Lift coefficient, $\left.\overline{C_{l}}\right|_{\text {opt }}$ & 2.827 \\
Drag coefficient $\left.\overline{C_{d}}\right|_{o p t}$ & 0.155 \\
\hline
\end{tabular}

The unsteady simulation revealed an almost unchanged lift coefficient and a more penalising drag coefficient. Figure 15 shows a colour map of the Mach distribution around the morphed airfoil, as well as the instantaneous flow streamline pattern at the last time-step.

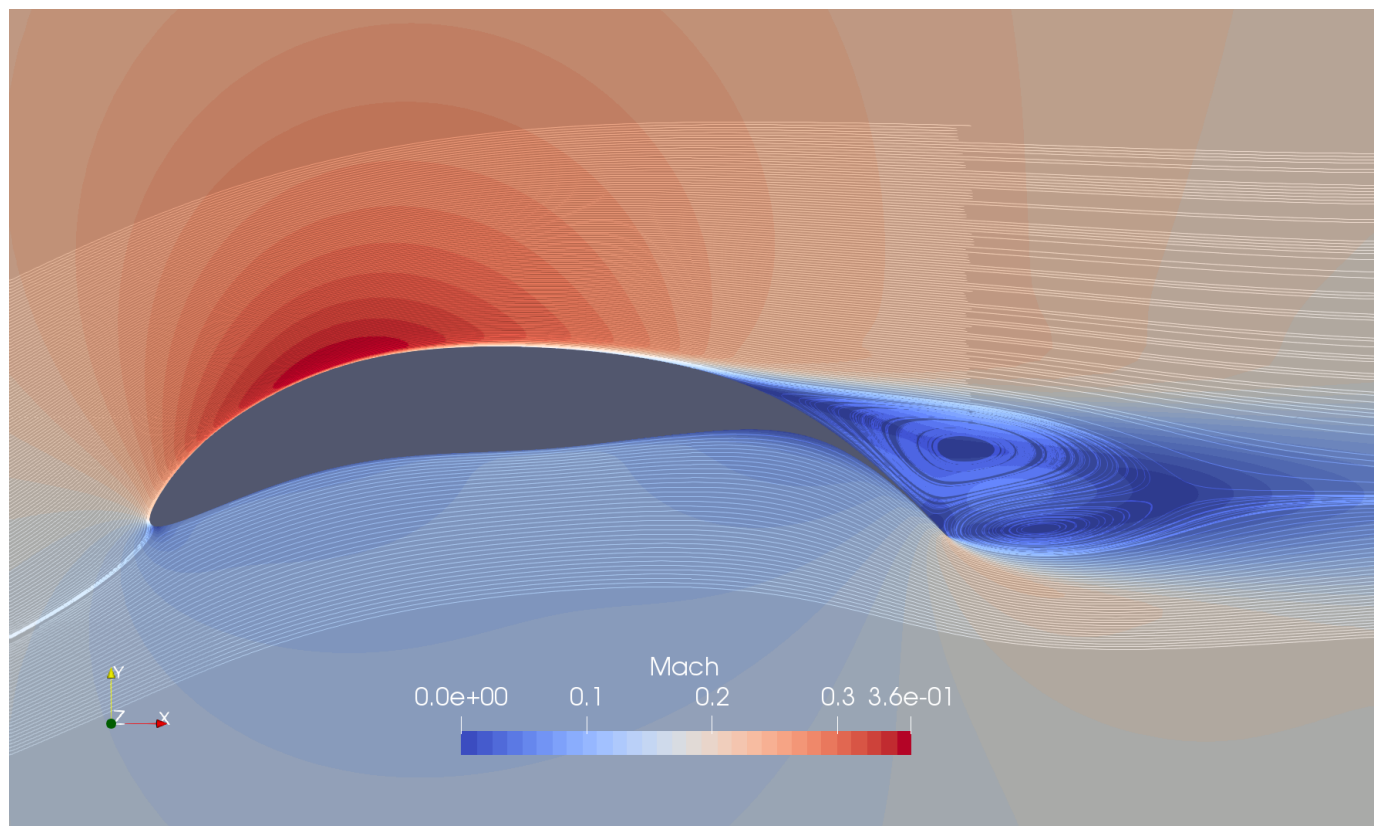

Figure 15. Flow visualisation on the definitive morphed airfoil for $M_{\infty}=0.185$ and $\alpha=10.1^{\circ}$.

The unsteady RANS and Spalart-Allmaras turbulence model coupling predicts the presence of a pair of oscillating mean separation bubbles at the morphed airfoil's trailing edge. Hence, it becomes now evident that this unsteady feature is the cause of a dramatic 
drag increase. The hypothesis from Section 4.1.2, where a locally stalled feature on this area was predicted, materialises. It is imperative to mention that no vortex shedding occurs and the pair of recirculating mean bubbles remain oscillating but always on the trailing edge. This behaviour might show the limitations of the Spalart-Allmaras turbulence model against large unsteady features such as these.

\subsection{Aeroacoustic Prediction}

The far-field aeroacoustic contribution was focused on the comparison of the main configurations of the present work: the baseline NLR7301 airfoil plus a trailing-edge flap, and the resulting morphed airfoil from the shape design optimisation. In this work, far-field aeroacoustic noise predictions have been obtained from surface pressure data provided by dual-time-stepping unsteady simulations along a certain time-span. In order to be consistent along the development of the work, a time-step of $\Delta_{t}=1 \mathrm{~ms}$ was again set for the conventional flapped configuration, following the set-up for the unsteady simulation of the morphed airfoil from the previous section. The surface data sampling has been carried out for a time-span of $t=0.2 \mathrm{~s}$.

As the acoustic framework was originally built for three-dimensional computations, both configurations have been provided of thickness and hence converted into $8 \mathrm{~cm}$ span wings. Considering the limitations of the acoustic framework, a maximum of 89 panels have been used to discretise the wing along its span direction, the $z$ axis. With respect to the aerodynamic data and analogously to the geometrical extrusion to gain thickness, the surface pressure data have been replicated in the $z$ direction by means of the 89 airfoils used to discretise the wing. Consequently, the far-field noise predictions describe aeroacoustic noise sources of a bi-dimensional nature. Lastly, the far-field noise predictions have been calculated at several observer locations, acting as an array of microphones around each of the configurations and forming a circle in the $x y$ plane with a radius of $R=2 \mathrm{~m}$, spaced every $\Delta\left(^{\circ}\right)=10^{\circ}$.

Regarding the conventional flapped configuration, the noise contributions of the two elements have been computed separately to be summed afterwards. In all the acoustic data generated, one can observe the higher amplitude of the loading noise, or dipole sources, with respect to the thickness noise, meaning that the aerodynamic loads have a greater contribution to overall noise than the purely geometrical, monopole sources. This statement can be particularly visualised through the Sound Pressure Levels (SPL) expressed in third-octave bands for these two noise sources in Figures 16 and 17, where the loading noise's Sound Pressure Levels (SPL) are substantially greater than the thickness noise's, by $25 \mathrm{~dB}$ in the case of the dominant frequency $f=1000 \mathrm{~Hz}$.

The total noise computation allows a comparison among the overall noise contributions from each configuration. Hence, the corresponding SPL values expressed in one-third octave bands for the NLR7301 and its trailing-edge flap are depicted in Figures 18 and 19, respectively, both having a very similar pyramidal trend to the SPL plots from the NACA 0012 shown by Brooks [37] at very similar velocities.

In contrast, the morphed airfoil SPL one-third octave bands slightly differ from the flapped configuration, where a contribution at low frequencies around $f=50 \mathrm{~Hz}$ arises, reaching a maximum value slightly above $40 \mathrm{~dB}$, depicted in Figure 20. A study of the flow features and self-noise of airfoils near stall or in stall [48] showed exactly the same phenomenon on experimental far-field data on a NACA 0012 at $\alpha=10.8^{\circ}$, in which deep stall effects such as vortex shedding were found to have an influence on the low frequency range, presenting peaks in the frequency spectrum up to $50 \mathrm{~dB}$, which are the signature of stall conditions, also appearing in other experimental works, such as [49]. This result suggests that the unsteady fluctuations on the trailing edge are at least partially captured and transmitted to the observer's location. 


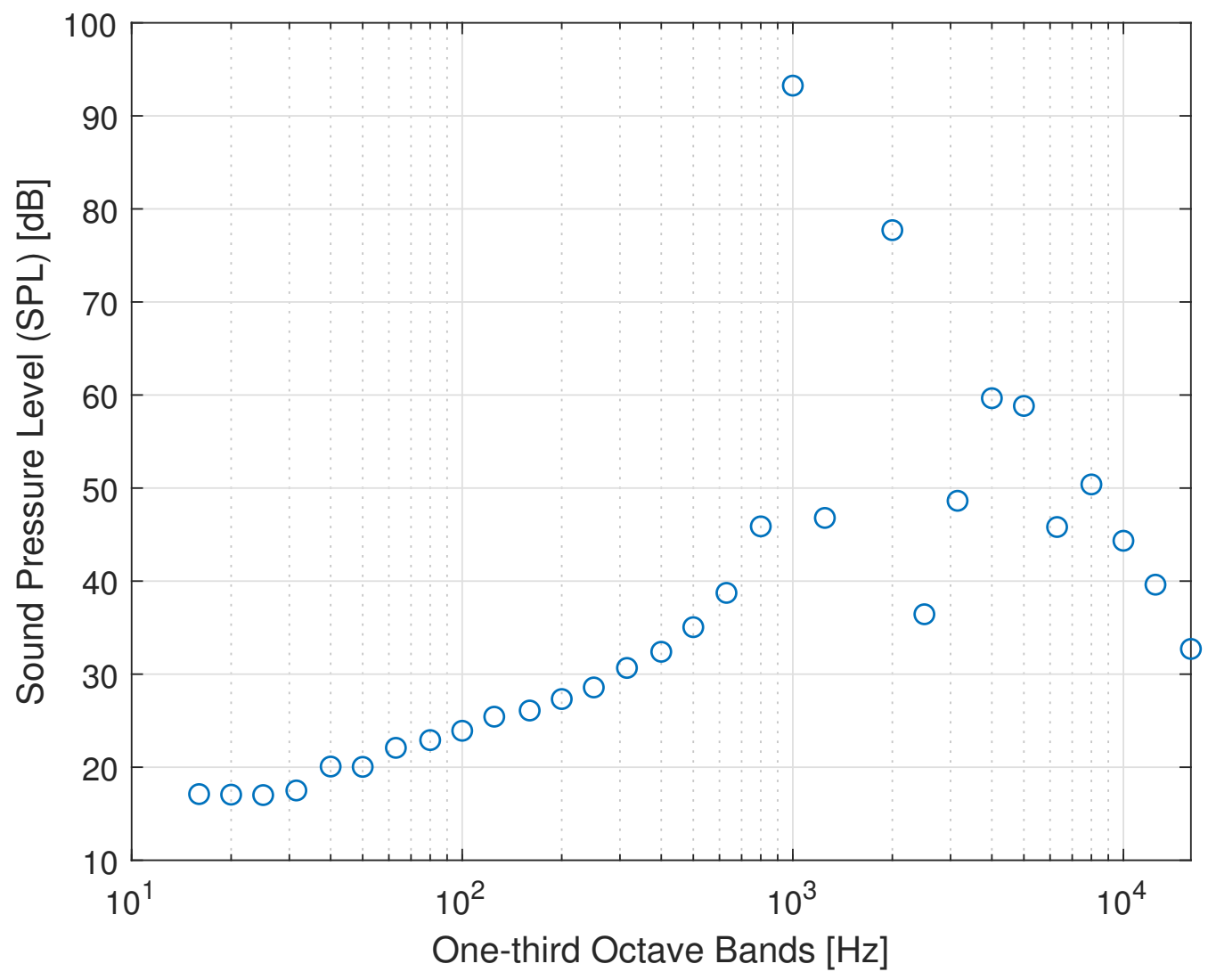

Figure 16. NLR7301 loading noise one-third octave bands at azimuthal position of $90^{\circ}$.

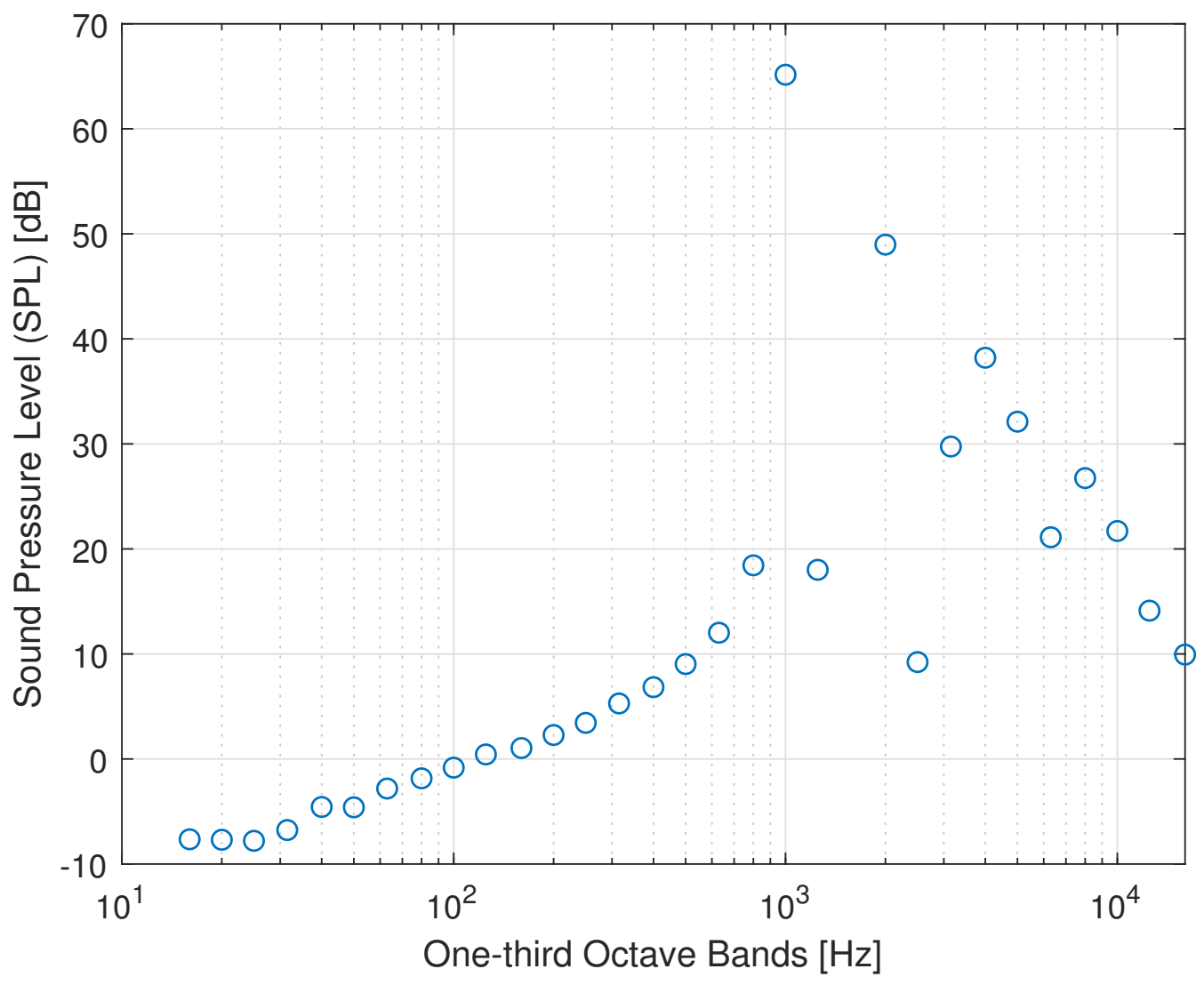

Figure 17. NLR7301 thickness noise one-third octave bands at azimuthal position of $90^{\circ}$. 


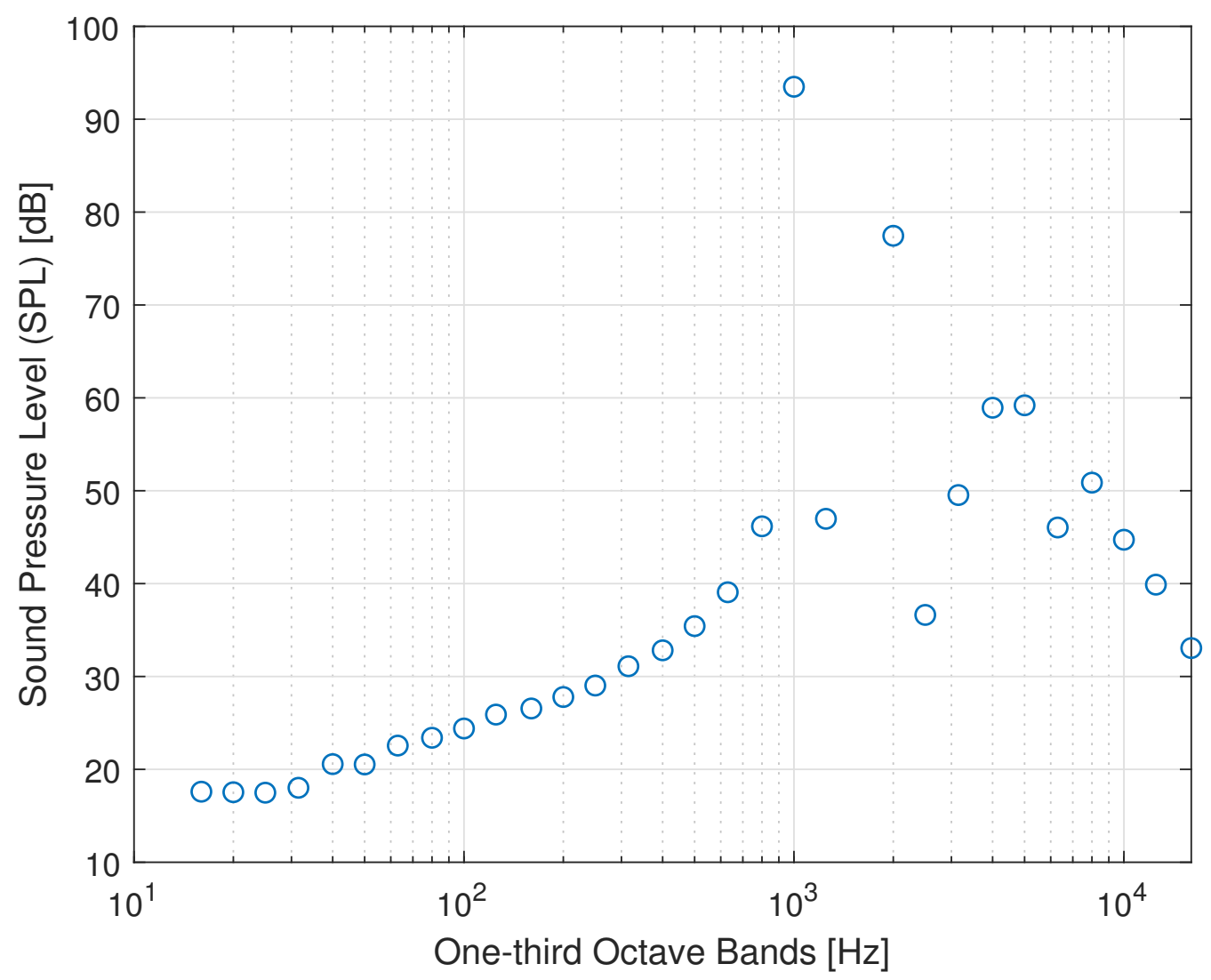

Figure 18. NLR7301 total noise one-third octave bands at azimuthal angle of $90^{\circ}$.

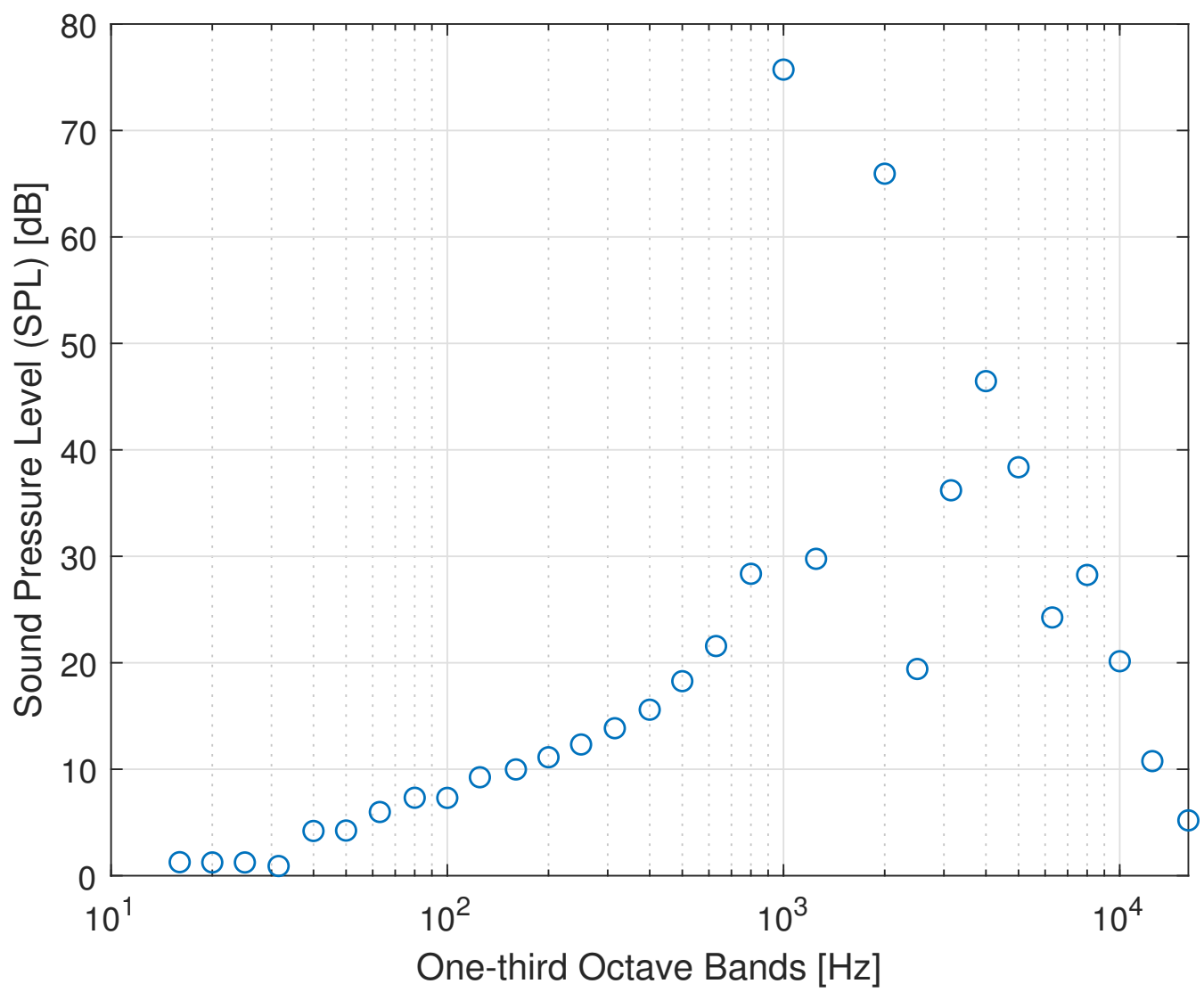

Figure 19. Trailing-edge flap total noise one-third octave bands at azimuthal angle of $90^{\circ}$. 


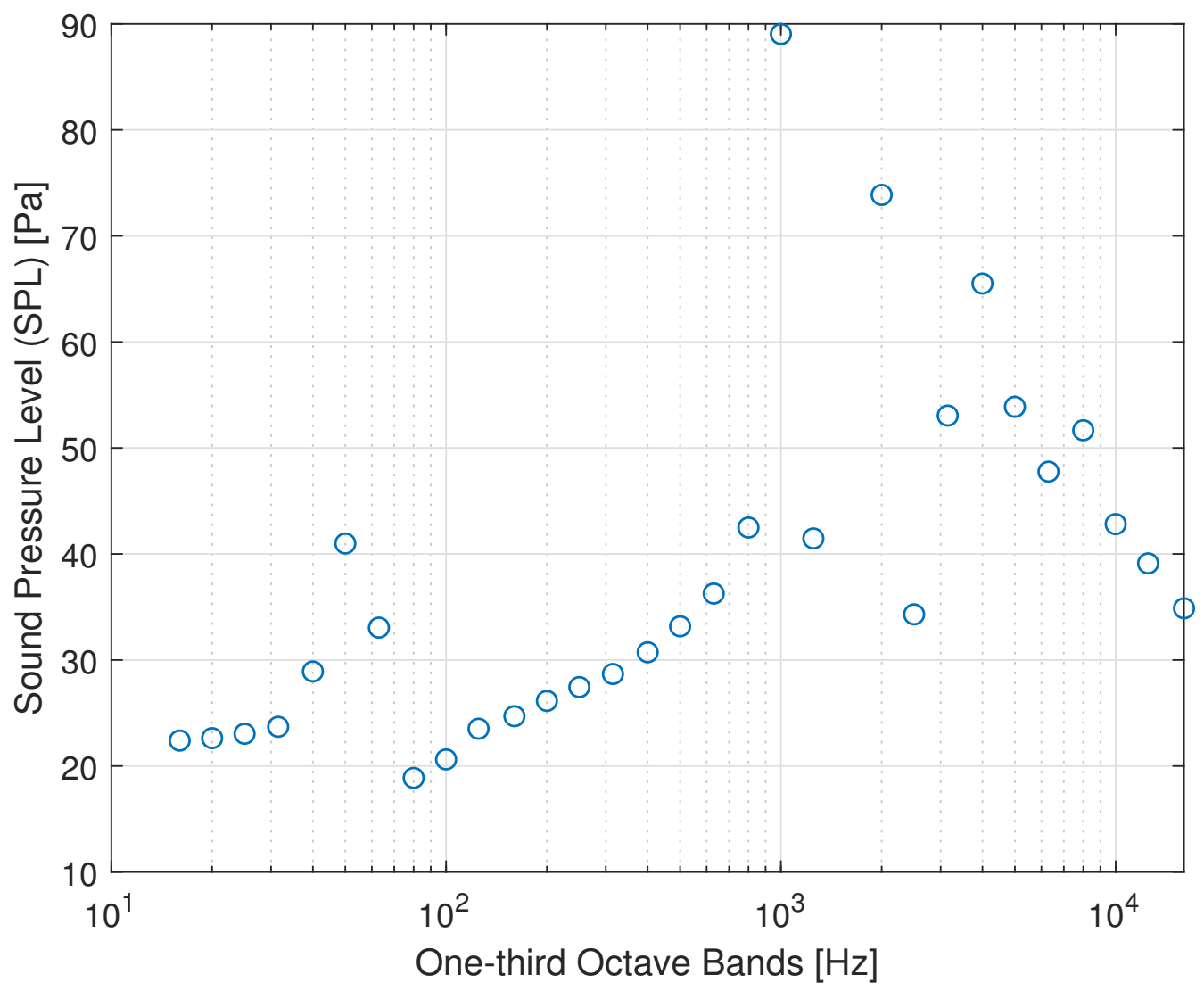

Figure 20. Morphed airfoil total noise one-third octave bands at azimuthal angle of $90^{\circ}$.

A very important matter must be addressed when computing the Overall Sound Pressure Levels (OASPL) at the different azimuthal locations around the morphing airfoil. As the acoustic framework of the present work computes the total noise emitted only by surface pressure fluctuations, the noise emitted by, for example, vortex shedding features from stall conditions is not accounted for, and this must be taken into account in the OASPL values. Regarding the noise estimation of an airfoil at a deep stall, works such as [50] have quantified an increase in Sound Pressure Levels up to $10 \mathrm{~dB}$ in such circumstances. Nevertheless, the morphing airfoil is not under deep stall conditions and such increments might not be achieved.

Even though some trailing-edge unsteadiness might have been captured, in order to provide a more conservative approach to the matter, a hypothetical overall increase of $10 \mathrm{~dB}$ for all OASPL values is also displayed in Figure 21, alongside the calculated ones for the conventional configuration, and the "clean" OASPL prediction for the morphed airfoil. The smoothness of the OASPL spatial distribution shows compactness, meaning that the time-step used for the simulations is adequate to properly represent the OASPL directivity.

Regarding the calculated OASPL for the morphed airfoil, remarkable improvements (positive values in Figure 22) are achieved at all observer locations up to $\approx 22 \%$ with respect to the conventional high-lift configuration. On the other hand, if the conservative increase of $10 \mathrm{~dB}$ on the morphed OASPL values is applied, local noise penalisation arises in some observer locations, as seen in Figure 23, where the maximum penalisation barely reaches $2 \%$ with respect to the high-lift configuration, in contrast with the $12 \%$ maximum improvement. 


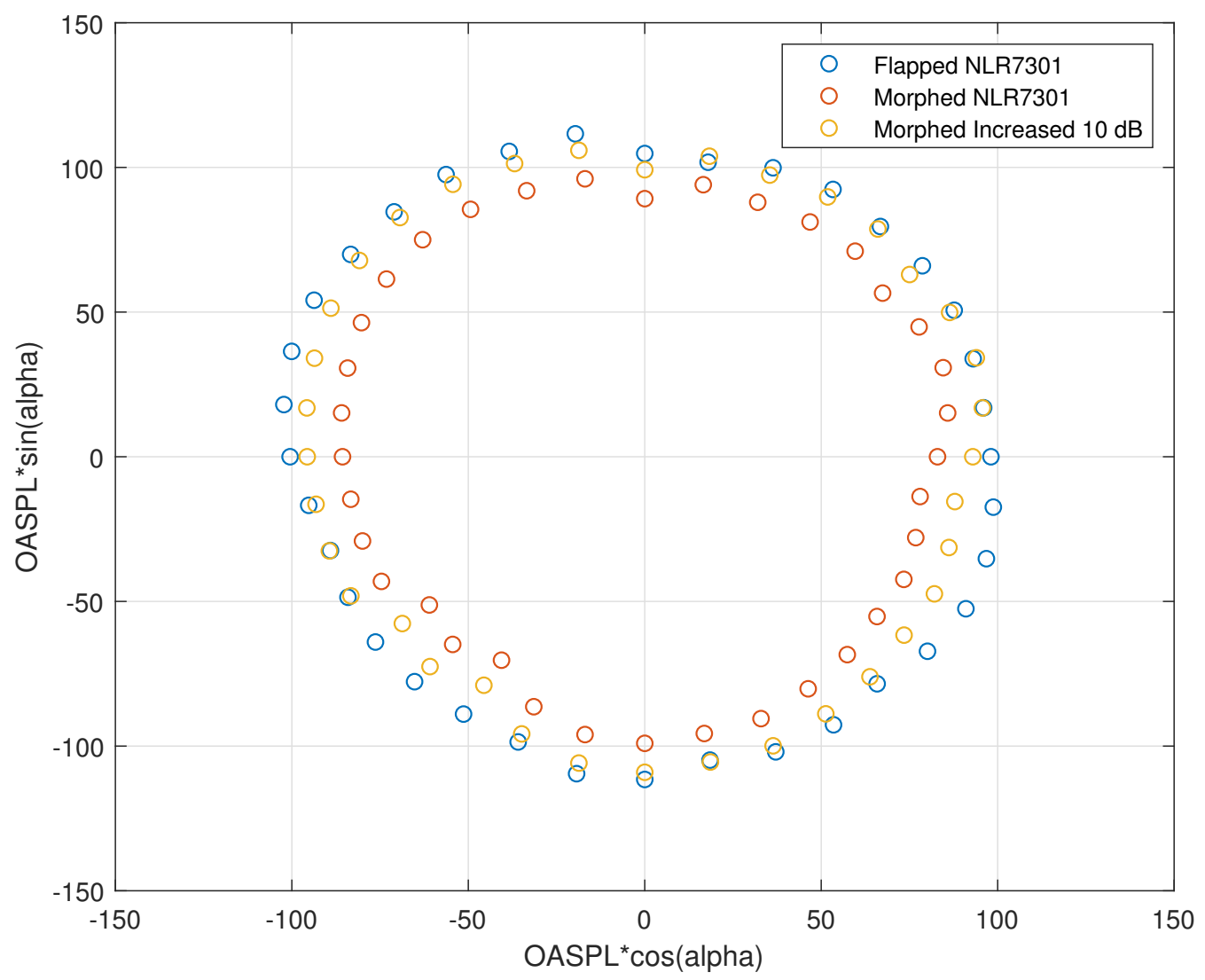

Figure 21. OASPL comparison for the NLR7301 plus trailing-edge flap and morphed airfoil.

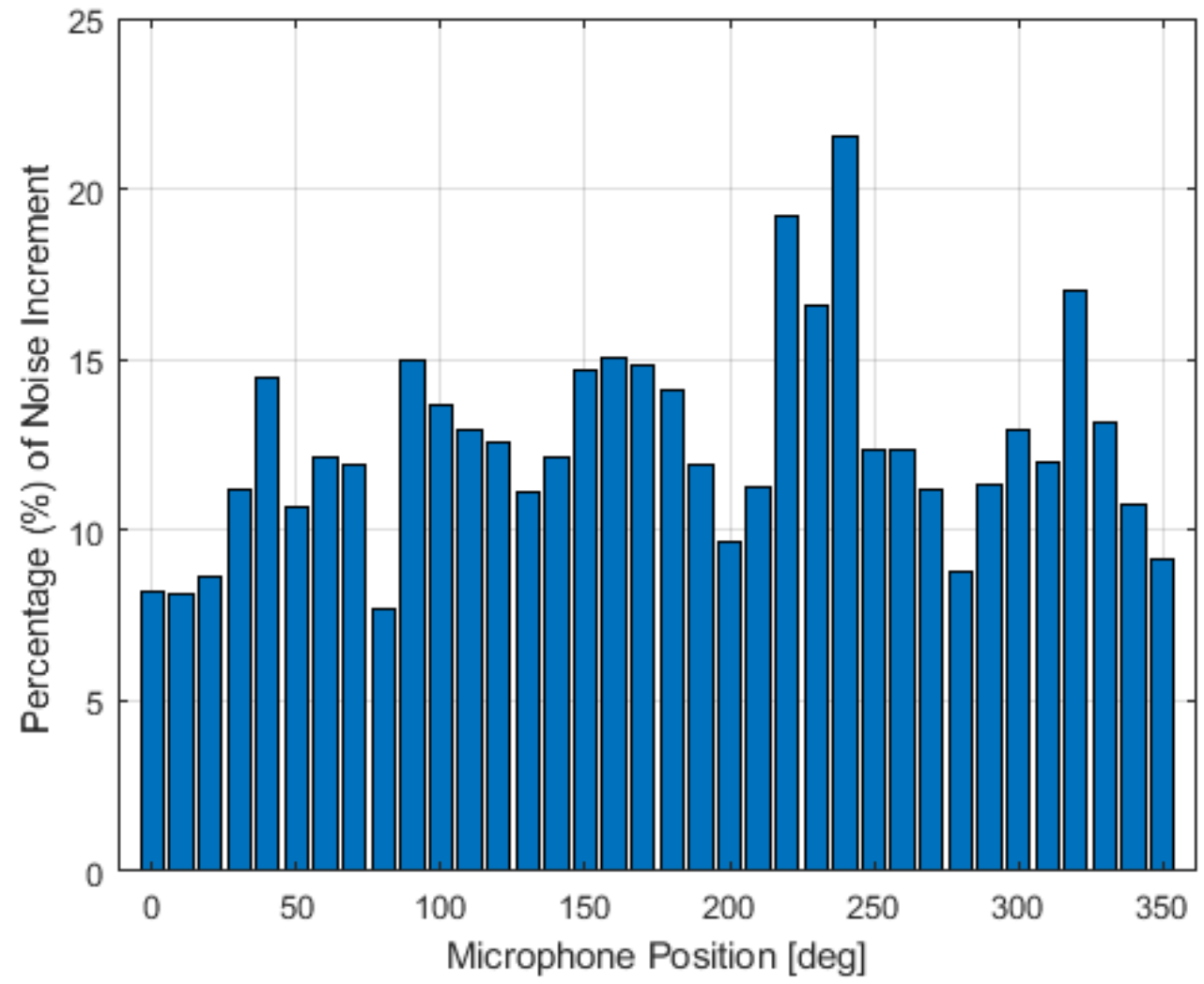

Figure 22. OASPL comparative results between flapped and morphed airfoils, for a set of microphones spaced $10^{\circ}$ from each other. 


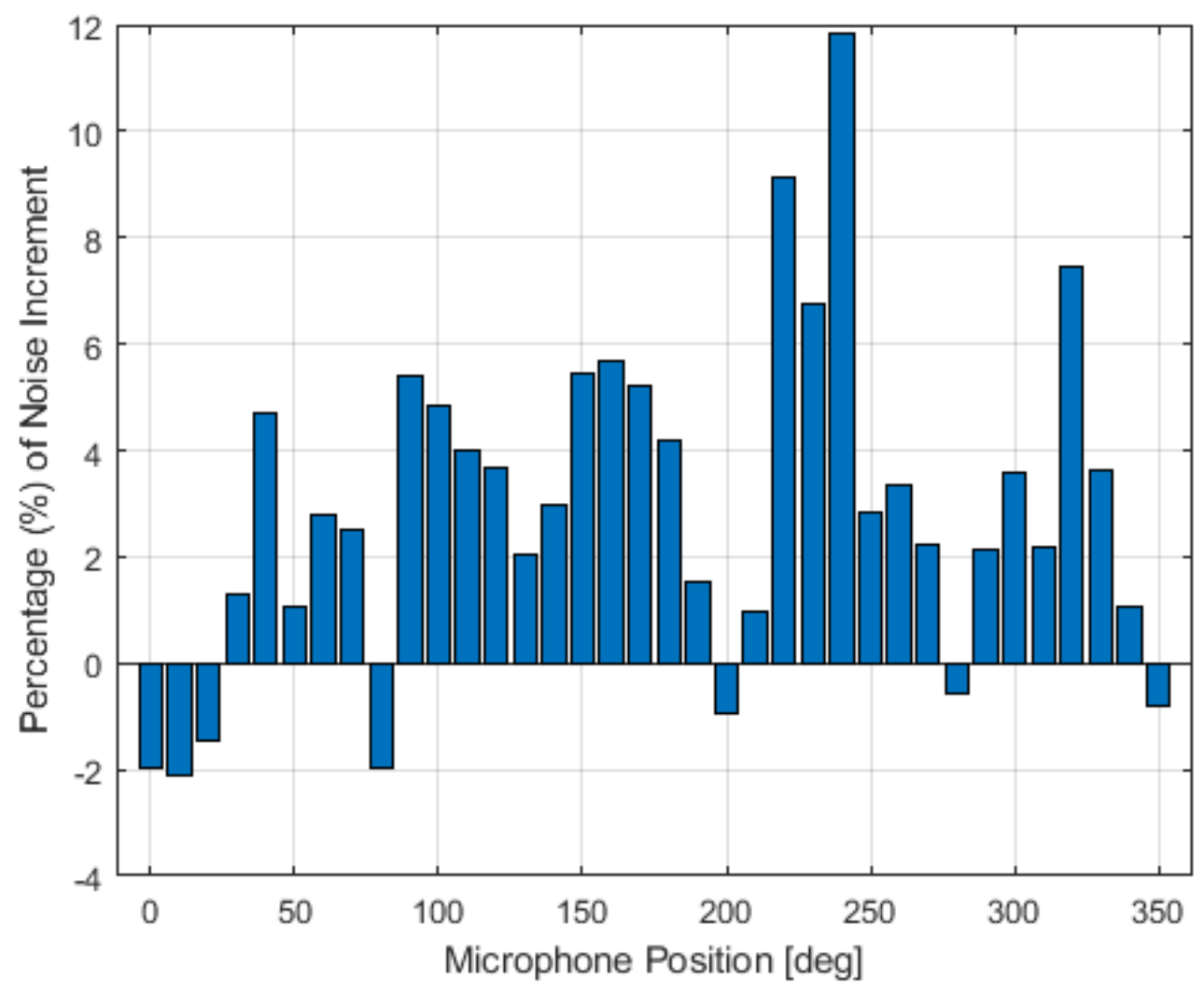

Figure 23. OASPL comparative results between flapped and conservative morphed airfoils, for a set of microphones spaced $10^{\circ}$ from each other.

\section{Conclusions}

The objectives of this work were to develop a methodology to perform a shape design optimisation of the NLR7301 two-dimensional airfoil section by means of the morphing concept, in order to achieve equivalent lifting capabilities to a high-lift configuration at takeoff and landing performance, composed of the NLR7301 baseline airfoil and a trailing-edge flap, to later obtain and compare each of the configurations' far-field noise contributions.

Validation test-cases have proven both CFD and aeroacoustic computational set-ups, mainly the RANS equations accompanied by the Spalart-Allmaras turbulence model in both steady and unsteady simulations, and the Farassat $1 \mathrm{~A}$ formulation for far-field noise prediction.

The definitive morphed airfoil has proven to be advantageous in terms of noise emissions for a comparable lift to that of the flapped configuration for the present work's computational set-up, up to a $22 \%$ relative noise reduction, even for a conservative case of an overall noise increase of $10 \mathrm{~dB}$ due to stall, where the maximum local noise increase does not surpass $2 \%$ with respect to the conventional configuration, in contrast with a maximum relative decrease of $12 \%$. Nevertheless, these achievements come with a significant penalisation regarding the drag coefficient due to the presence of a set of two mean recirculation bubbles on its trailing edge.

Author Contributions: Conceptualization, R.V.M. and F.A.; methodology, R.V.M. and F.A.; software, R.V.M.; validation, R.V.M.; formal analysis, R.V.M.; investigation, R.V.M.; data curation, R.V.M. and F.A.; writing — original draft preparation, R.V.M.; writing-review and editing, F.A. and F.L.; visualization, R.V.M.; supervision, F.A. and F.L.; project administration, F.L.; funding acquisition, F.L. All authors have read and agreed to the published version of the manuscript.

Funding: F.A. and F.L. acknowledge Fundação para a Ciência e a Tecnologia (FCT), through IDMEC, under LAETA, project UIDB/50022/2020.

Institutional Review Board Statement: Not applicable. 
Informed Consent Statement: Not applicable.

Data Availability Statement: The new data presented in this study are available on request from the corresponding author.

Conflicts of Interest: The authors declare no conflicts of interest.

\section{References}

1. Smith, M.J.T. Aircraft Noise; Cambridge Aerospace Series; Cambridge University Press: Cambridge, UK, 1989. [CrossRef]

2. Hayes, J.; Horne, W.; Soderman, P.; Bent, P. Airframe noise characteristics of a 4.7 percent scale DC-10 model. In Proceedings of the 3rd AIAA/CEAS Aeroacoustics Conference, Atlanta, GA, USA, 12-14 May 1997. [CrossRef]

3. Meadows, K.; Brooks, T.; Humphreys, W.; Hunter, W.; Gerhold, C. Aeroacoustic measurements of a wing-flap configuration. In Proceedings of the 3rd AIAA/CEAS Aeroacoustics Conference, Atlanta, GA, USA, 12-14 May 1997. [CrossRef]

4. Radeztsky, R., Jr.; Singer, B.; Khorrami, M. Detailed measurements of a flap side-edge flow field. In Proceedings of the 36th AIAA Aerospace Sciences Meeting and Exhibit, Reno, NV, USA, 12-15 January 1998. [CrossRef]

5. Kendall, J.; Ahtye, W. Noise generation by a lifting wing/flap combination at Reynolds numbers to $2.8 \times 10$ to the 6 th. In Proceedings of the 18th Aerospace Sciences Meeting, Pasadena, CA, USA, 14-16 January 1980. [CrossRef]

6. Dobrzynski, W.; Nagakura, K.; Gehlhar, B.; Buschbaum, A. Airframe noise studies on wings with deployed high-lift devices. In Proceedings of the 4th AIAA/CEAS Aeroacoustics Conference, Toulouse, France, 2-4 June 1998. [CrossRef]

7. Perennes, S.; Roger, M. Aerodynamic noise of a two-dimensional wing with high-lift devices. In Proceedings of the 4th AIAA/CEAS Aeroacoustics Conference, Toulouse, France, 2-4 June 1998. [CrossRef]

8. European Commission. Flightpath 2050 Vision for European Aviation; Report of the High Level Group on Aviation Research; Publications Office of the European Union: Luxembourg, 2011; ISBN 978-92-79-19724-6.

9. Smith, M.S.; Bui, T.T.; Garcia, C.A.; Cumming, S.B. Longitudinal Aerodynamic Modeling of the Adaptive Compliant Trailing Edge Flaps on a GIII Aircraft and Comparisons to Flight Data. In Proceedings of the AIAA Atmospheric Flight Mechanics Conference, Washington, DC, USA, 13-17 June 2016. [CrossRef]

10. Hetrick, J.A.; Kota, S.; Ervin, G.F. Compliant Structure Design of Varying Surface Contours. US Patent 8,418,966, 16 April 2013.

11. Herrera, C. Adaptive Compliant Trailing Edge (ACTE) Flight Testing; EAA AirVenture: Nekimi, WI, USA, 2018. Available online: https:/ /ntrs.nasa.gov/ citations / 20180005456 (accessed on 20 December 2021).

12. The Boeing Preliminary Design Department. Assessment of Variable Camber for Application to Transport Aircraft; Technical Report CR-1589305; National Aeronautics and Space Administration Langley Research Center: Hampton, VA, USA, 1980.

13. Schorsch, O.; Nagel, C.; Lühring, A. Chapter 7-Morphing Skin: Foams. In Morphing Wing Technologies; Concilio, A., Dimino, I., Lecce, L., Pecora, R., Eds.; Butterworth-Heinemann: Oxford, UK, 2018; pp. 207-230. [CrossRef]

14. Vigliotti, A.; Pasini, D. Chapter 8-The Design of Skin Panels for Morphing Wings in Lattice Materials. In Morphing Wing Technologies; Concilio, A., Dimino, I., Lecce, L., Pecora, R., Eds.; Butterworth-Heinemann: Oxford, UK, 2018; pp. 231-246. [CrossRef]

15. Airoldi, A.; Sala, G.; Di Landro, L.A.; Bettini, P.; Gilardelli, A. Chapter 9-Composite Corrugated Laminates for Morphing Applications. In Morphing Wing Technologies; Concilio, A., Dimino, I., Lecce, L., Pecora, R., Eds.; Butterworth-Heinemann: Oxford, UK, 2018; pp. 247-276. [CrossRef]

16. Tani, Y.; Yamashita, Y.; Miyazaki, K.; Aso, S.; Ura, H.; Ito, T. Morphing Flap Concept to Reduce the Flap Side Edge Noise for Aircraft Wing Slotted Flaps. In Proceedings of the 52nd Aerospace Sciences Meeting, National Harbor, MD, USA, 13-17 January 2014. [CrossRef]

17. Wölcken, P.C.; Papadopoulos, M. (Eds.) Smart Intelligent Aircraft Structures (SARISTU); Springer International Publishing: Berlin/Heidelberg, Germany, 2016. [CrossRef]

18. Urnes, J.; Nguyen, N. A Mission Adaptive Variable Camber Flap Control System to Optimize High Lift and Cruise Lift to Drag Ratios of Future N+3 Transport Aircraft. In Proceedings of the 51st AIAA Aerospace Sciences Meeting including the New Horizons Forum and Aerospace Exposition, Grapevine, TX, USA, 7-10 January 2013. [CrossRef]

19. Bui, T.T. Analysis of Low-Speed Stall Aerodynamics of a Swept Wing with Seamless Flaps. In Proceedings of the 34th AIAA Applied Aerodynamics Conference, Washington, DC, USA, 13-17 June 2016. [CrossRef]

20. Rumsey, C.L.; Ying, S.X. Prediction of high lift: Review of present CFD capability. Prog. Aerosp. Sci. 2002, 38, 145-180. [CrossRef]

21. Lighthill, M.J.; Newman, M.H.A. On sound generated aerodynamically I. General theory. Proc. R. Soc. Lond. Ser. A. Math. Phys. Sci. 1952, 211, 564-587. [CrossRef]

22. Khorrami, M.R.; Singer, B.A.; Takallu, M.A. Analysis of Flap Side-Edge Flowfield for Identification and Modeling of Possible Noise Sources. SAE Trans. 1997, 106, 2716-2722.

23. van den Berg, B. Boundary Layer Measurements on a Two-Dimensional Wing with Flap; Technical Report NLR-TR 79009 U; National Aerospace Laboratory: Amsterdam, The Netherlands, 1979.

24. Economon, T.D.; Palacios, F.; Copeland, S.R.; Lukaczyk, T.W.; Alonso, J.J. SU2: An Open-Source Suite for Multiphysics Simulation and Design. AIAA J. 2016, 54, 828-846. [CrossRef]

25. Roe, P.L. Approximate Riemann solvers, parameter vectors, and difference schemes. J. Comput. Phys. 1981, 43, 357-372. [CrossRef] 
26. van Leer, B. Towards the ultimate conservative difference scheme. V. A second-order sequel to Godunov's method. J. Comput. Phys. 1979, 32, 101-136. [CrossRef]

27. Venkatakrishnan, V. On the accuracy of limiters and convergence to steady state solutions. In Proceedings of the 31st Aerospace Sciences Meeting, Reno, NV, USA, 11-14 January 1993. [CrossRef]

28. Toro, E.F. High-Order and TVD Methods for Scalar Equations. In Riemann Solvers and Numerical Methods for Fluid Dynamics: A Practical Introduction; Springer: Berlin/Heidelberg, Germany, 2009; pp. 413-492. [CrossRef]

29. Moukalled, F.; Mangani, L.; Darwish, M. The Finite Volume Method in Computational Fluid Dynamics. An Advanced Introduction with OpenFOAM and Matlab; Springer International Publishing: Berlin/Heidelberg, Germany, 2016. [CrossRef]

30. Spalart, P.; Allmaras, S. A one-equation turbulence model for aerodynamic flows. In Proceedings of the 30th Aerospace Sciences Meeting and Exhibit, Reno, NV, USA, 6-9 January 1992. [CrossRef]

31. Godin, P.; Zingg, D.W.; Nelson, T.E. High-Lift Aerodynamic Computations with One- and Two-Equation Turbulence Models. AIAA J. 1997, 35, 237-243. [CrossRef]

32. Rumsey, C.L.; Gatski, T.B.; Ying, S.X.; Bertelrud, A. Prediction of High-Lift Flows Using Turbulent Closure Models. AIAA J. 1998, 36, 765-774. [CrossRef]

33. Nadarajah, S.; Jameson, A. A comparison of the continuous and discrete adjoint approach to automatic aerodynamic optimization In Proceedings of the 38th Aerospace Sciences Meeting and Exhibit, Reno, NV, USA, 10-13 January 2000. [CrossRef]

34. Sederberg, T.W.; Parry, S.R. Free-Form Deformation of Solid Geometric Models. In SIGGRAPH 86, Proceedings of the 13th Annual Conference on Computer Graphics and Interactive Techniques, New York, NY, USA, August 1986; Association for Computing Machinery: New York, NY, USA, 1986; pp. 151-160. [CrossRef]

35. Sarakinos, S.S.; Amoiralis, E.; Nikolos, I.K. Exploring Freeform Deformation Capabilities in Aerodynamic Shape Parameterization. In Proceedings of the EUROCON 2005-The International Conference on Computer as a Tool, Serbia \& Montenegro, Belgrade, Serbia, 22-24 November 2005. [CrossRef]

36. Lyu, Z.; Martins, J.R.R.A. Aerodynamic Shape Optimization of an Adaptive Morphing Trailing-Edge Wing. J. Aircr. 2015, 52, 1951-1970. [CrossRef]

37. Brooks, T.; Pope, D.; Marcolini, M. Airfoil Self-Noise and Prediction; Technical Report NASA-RP-1218; NASA Langley Research Center: Hampton, VA, USA, 1989.

38. Souto, J. Development of an Aeroacoustic Prediction Tool for Wind Turbine Noise. Master's Thesis, Instituto Superior Técnico, Universidade de Lisboa, Lisbon, Portugal, 2017.

39. Ffowcs Williams, J.E.; Hawkings, D.L.; Lighthill, M.J. Sound generation by turbulence and surfaces in arbitrary motion. Philos. Trans. R. Soc. London. Ser. A Math. Phys. Sci. 1969, 264, 321-342. [CrossRef]

40. Brentner, K.S.; Farassat, F. Modeling aerodynamically generated sound of helicopter rotors. Prog. Aerosp. Sci. 2003, 39, 83-120. [CrossRef]

41. Curle, N.; Lighthill, M.J. The influence of solid boundaries upon aerodynamic sound. Proc. R. Soc. London. Ser. A. Math. Phys. Sci. 1955, 231, 505-514. [CrossRef]

42. Farassat, F. Theory of Noise Generation from Moving Bodies with an Application to Helicopter Rotors; Technical Report; NASA Langley: Hampton, VA, USA, 1975.

43. León, C.A.; Merino-Martínez, R.; Ragni, D.; Avallone, F.; Snellen, M. Boundary layer characterization and acoustic measurements of flow-aligned trailing edge serrations. Exp. Fluids Vol. 2016, 57, 91. [CrossRef]

44. Smith, A.M.O. High Lift Aerodynamics. J. Aircr. 1975, 12, 501-530. [CrossRef]

45. Bindolino, G.; Ghiringhelli, G.; Ricci, S.; Terraneo, M. Multilevel Structural Optimization for Preliminary Wing-Box Weight Estimation. J. Aircr. 2010, 47, 475-489. [CrossRef]

46. Dabaneh, O.; Kipouros, T. Influence of High Fidelity on the Predicted Mass of the Aircraft Wing Using Design Optimization. Aerosp. Sci. Technol. 2018, 79, 164-173. [CrossRef]

47. Deblois, A.; Abdo, M. Multi-Fidelity Multidisciplinary Design Optimization of Metallic and Composite Regional and Business Jets. In Proceedings of the 13th AIAA/ISSMO Mulitidisciplinary Analysis Optimization Conference, Fort Worth, TX, USA, 13-15 September 2010.

48. Moreau, S.; Roger, M.; Christophe, J. Flow Features and Self-Noise of Airfoils Near Stall or in Stall. In Proceedings of the 15th AIAA/CEAS Aeroacoustics Conference (30th AIAA Aeroacoustics Conference), Miami, FL, USA, 11-13 May 2009. [CrossRef]

49. Laratro, A.; Arjomandi, M.; Cazzolato, B.; Kelso, R. Self-noise and directivity of simple airfoils during stall: An experimental comparison. Appl. Acoust. 2017, 127, 133-146. [CrossRef]

50. Fink, M.R.; Bailey, D.A. Airframe Noise Reduction Studies and Clean-Airframe Noise Investigation; Technical Report NASA-CR-159311, R80-914626-12; United Technologies Research Center: East Hartford, CT, USA, 1980. 